\title{
Insulin Aspart in the Management of Diabetes Mellitus: 15 Years of Clinical Experience
}

\author{
Kjeld Hermansen $^{1} \cdot$ Mette Bohl $^{1} \cdot$ Anne Grethe Schioldan $^{1}$
}

Published online: 25 November 2015

(C) The Author(s) 2015. This article is published with open access at Springerlink.com

\begin{abstract}
Limiting excessive postprandial glucose excursions is an important component of good overall glycemic control in diabetes mellitus. Pharmacokinetic studies have shown that insulin aspart, which is structurally identical to regular human insulin except for the replacement of a single proline amino acid with an aspartic acid residue, has a more physiologic time-action profile (i.e., reaches a higher peak and reaches that peak sooner) than regular human insulin. As expected with this improved pharmacokinetic profile, insulin aspart demonstrates a greater glucose-lowering effect compared with regular human insulin. Numerous randomized controlled trials and a meta-analysis have also demonstrated improved postprandial control with insulin aspart compared with regular human insulin in patients with type 1 or type 2 diabetes, as well as efficacy and safety in children, pregnant patients, hospitalized patients, and patients using continuous subcutaneous insulin infusion. Studies have demonstrated that step-wise addition of insulin aspart is a viable intensification option for patients with type 2 diabetes failing on basal insulin. Insulin aspart has shown a good safety profile, with no evidence of increased receptor binding, mitogenicity, stimulation of anti-insulin antibodies, or hypoglycemia compared with regular human insulin. In one metaanalysis, there was evidence of a lower rate of nocturnal hypoglycemia compared with regular human insulin and, in a trial that specifically included patients with a history of recurrent hypoglycemia, a significantly lower rate of severe
\end{abstract}

Kjeld Hermansen

kjeld.hermansen@aarhus.rm.dk

1 Department of Endocrinology and Internal Medicine, Aarhus University Hospital, Tage-Hansens Gade 2, 8000 Aarhus C, Denmark hypoglycemic episodes. The next generation of insulin aspart (faster-acting insulin aspart) is being developed with a view to further improving on these pharmacokinetic/ pharmacodynamic properties.

\section{Key Points}

Insulin aspart has an improved pharmacokinetic profile compared with regular human insulin and thus demonstrates a greater glucose-lowering effect.

The safety and efficacy of insulin aspart has been demonstrated via randomized controlled trials in diverse patient populations with type 1 or type 2 diabetes mellitus.

Step-wise intensification is an appropriate treatment option with insulin aspart.

There is some evidence that patients with a history of recurrent hypoglycemia may have a lower incidence of severe episodes using insulin aspart.

\section{Introduction}

Recent global data continue to confirm that the number of people with diabetes mellitus is increasing worldwide, with 387 million people ( $8.3 \%$ of the world's population) living with diabetes in 2014 [1]. Landmark trials such as the Diabetes Control and Complications Trial (DCCT) and its observational follow-up trial (Epidemiology of Diabetes 
Interventions and Complications; EDIC) in type 1 diabetes (T1D) [2-6] and the United Kingdom Prospective Diabetes Study (UKPDS) in type 2 diabetes (T2D) [7-9] have demonstrated the importance of achieving glycemic control as close to the non-diabetic range as safely as possible in order to reduce the risk of microvascular complications. Implications for preventing macrovascular disease are less clear, as subsequent randomized trials have produced results challenging the idea that aggressive glucose control should be pursued in all patients due to increased risk of adverse events [10-15]. Thus, guidelines recommend that the decision to pursue tight glucose control in T2D, typically as measured by glycated hemoglobin $\left(\mathrm{HbA}_{1 \mathrm{c}}\right)$, is one that should be tailored carefully to individual patients [16]. Early intensive therapy may be more suitable for younger patients with a shorter duration of disease, with less aggressive therapy being considered for older patients with long-standing diabetes and a history of cardiovascular disease (CVD) or other comorbidities [11-13, 16, 17].

A limitation of using $\mathrm{HbA}_{1 \mathrm{c}}$ to assess the adequacy of glycemic control is that patients may have acceptable overall $\mathrm{HbA}_{1 \mathrm{c}}$ levels while still experiencing excessive elevations in postprandial glucose. The relative contribution of postprandial glucose excursions to overall hyperglycemia has been shown to be predominant in those patients with better glycemic control, in contrast to elevations in fasting blood glucose (FBG), which increases in contribution when patients have poorer control as measured by higher $\mathrm{HbA}_{1 \mathrm{c}}$ [18]. Some studies have indicated that postprandial glucose is a predictor of CVD or mortality independent of fasting glucose levels [19-24]; however, the current evidence for this is still highly controversial [25].

At concentrations found in pharmaceutical formulations, monomers of regular human insulin (RHI) form dimers, which in the presence of zinc ions at neutral $\mathrm{pH}$ tend to assemble into larger hexamers [26, 27]. This self-assembly has the undesirable effect of delaying absorption after subcutaneous (SC) injection, as the hexamers must first dissociate before they can be absorbed into the bloodstream via capillaries in the SC tissue [28]. Delayed absorption of RHI can fail to prevent excessive postprandial glucose excursions, resulting in suboptimal glycemic control. Prolonged duration of action could lead to delayed hypoglycemia, including nocturnal episodes $[29,30]$. The nonphysiological action profile is also inconvenient for patients, who must inject 30 min prior to eating in order to better synchronize insulin availability with carbohydrate absorption [29, 31]. The rapid-acting analog, insulin aspart, introduced over 15 years ago, is formulated to attempt to overcome these limitations.

The goal of this review was to summarize 15 years of clinical experience with insulin aspart in diverse populations of patients with T1D or T2D. We identified medical literature in the English language since 2002 using Medline and The Cochrane Library. EMBASE was searched from 2010. Bibliographical information and abstracts were also provided by Novo Nordisk. The index terms used in Medline, EMBASE, and The Cochrane Library were insulin aspart, diabetes mellitus, insulin analog, pharmacodynamics, pharmacokinetics, and therapeutic use. Searches were last updated 11 May 2015. Pharmacodynamic and pharmacokinetic data and primary studies in patients with type 1 or 2 diabetes mellitus or gestational diabetes mellitus who received insulin aspart were included. We excluded studies on insulin aspart used in co-formulation with insulin degludec, studies of biphasic insulin aspart, basal-bolus studies where basal insulins were different in each arm but insulin aspart was used as bolus insulin in both study arms, individual case reports, use of insulin aspart in short-term intensive therapy for newly diagnosed patients, studies focusing primarily on delivery devices or inhaled insulin, in-vitro studies focusing on analog measurement techniques for insulin analogs, and studies conducted in animals. We also excluded trials where multiple rapid-acting analogs were administered or where the primary goal was to compare basal insulins and the results for insulin aspart could not be isolated.

\section{Pharmacokinetic and Pharmacodynamic Properties of Insulin Aspart}

\subsection{Structure}

Insulin aspart is structurally identical to both RHI and endogenous insulin, except for replacement of a single proline amino acid at position 28 in the C-terminal area of the insulin B-chain with an aspartic acid residue $[32,33]$. This substitution weakens the natural tendency towards self-association between insulin monomers, thereby inhibiting aggregation into hexamers and accelerating absorption after SC injection [26, 33]. Because the aspartic acid substitution on the B-chain does not involve the receptor portion of the insulin molecule, the structural change has no effect on the biological activity of insulin aspart in vivo [34].

\subsection{Pharmacokinetics (PK)}

\subsubsection{Comparison with Regular Insulin}

The pharmacokinetics (PK) of insulin aspart in healthy volunteers, in patients with diabetes, and in special populations has been reviewed [35]. For example, early studies in healthy volunteers using the euglycemic clamp method 
demonstrated that following injection into SC tissue, insulin aspart had faster absorption and higher peak serum levels than RHI [36-38]. A double-blind crossover study in 25 healthy men further demonstrated that the time-action profile of SC insulin aspart more closely resembled normal endogenous post-prandial release of insulin than RHI, achieving more than double the concentration and reaching maximum concentration $\left(C_{\max }\right)$ in less than half of the time [39] (Fig. 1a). Two studies in healthy Japanese males confirmed these PK properties [40].

These favorable PK trends are maintained in patients with T1D or T2D. In a double-blind, double-dummy crossover study in 22 people with T1D, insulin aspart administered immediately before a standard meal was compared with RHI administered immediately before or $30 \mathrm{~min}$ before a meal. The $C_{\max (i n s u l i n)}$ was almost twice as high for insulin aspart $(p<0.0001)$, and time to maximum concentration $\left(T_{\max (\text { insulin) }}\right)$ was reached at around $40 \mathrm{~min}$ after dosing for insulin aspart-approximately 60 and 40 min faster than RHI administered immediately before a meal or 30 min before a meal, respectively $(p<0.0001$ and $p<0.002$ ) [41] (Fig. 1b). Insulin aspart was also compared with RHI in a crossover study in 19 patients with T1D in which area under the concentration-time curve $\left(\mathrm{AUC}_{\text {insulin }}\right)$ was measured after $\mathrm{SC}$ administration, combined with consuming a standardized test meal [42]. $\mathrm{AUC}_{\text {insulin }}$ was significantly higher for insulin aspart compared with RHI at $0-4$ and $0-6 \mathrm{~h}(p<0.05)$.

When 20 subjects with T2D were evaluated following a single test meal, it was found that the PK properties of insulin aspart were preserved, but the $T_{\max }$ varied considerably among individual patients and was not correlated with dose in the range of $0.05-0.22 \mathrm{U} / \mathrm{kg}$ [43]. In a randomized, double-blind, crossover trial in 37 patients with $\mathrm{T} 2 \mathrm{D}$, serum insulin concentrations were measured for 240 min following meal ingestion [44] (Fig. 1c). Maximum serum insulin concentration and AUC insulin $_{0-4} \mathrm{~h}$ were higher $(p=0.023)$ and median time to maximum serum insulin concentration was $27 \mathrm{~min}$ shorter ( $p=0.039)$ for insulin aspart than for RHI.

A euglycemic clamp study in 20 non-diabetic subjects demonstrated that the more rapid absorption of insulin aspart compared with RHI was maintained regardless of site of administration (i.e., deltoid, abdomen, or thigh) [38]. However, it has been demonstrated that absorption may be impaired in lipohypertrophic tissue, with $C_{\max }$ reduced by as much as $25 \%$ in T1D [45].

Distributing the insulin injection volume over a broader area should theoretically enhance absorption. Two studies found improved PK with insulin aspart using a needle-free jet injector, which delivers insulin at high velocity, resulting in distribution over a larger tissue volume than a conventional pen device $[46,47]$. Both were randomized,

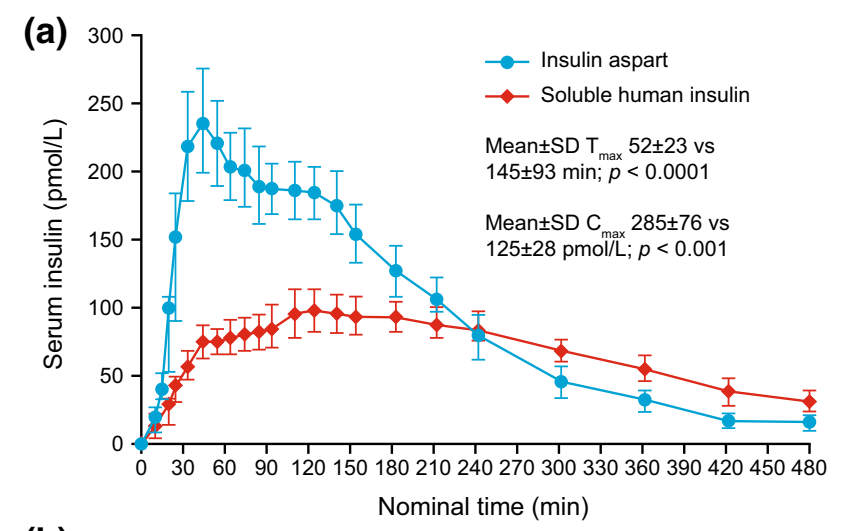

(b)
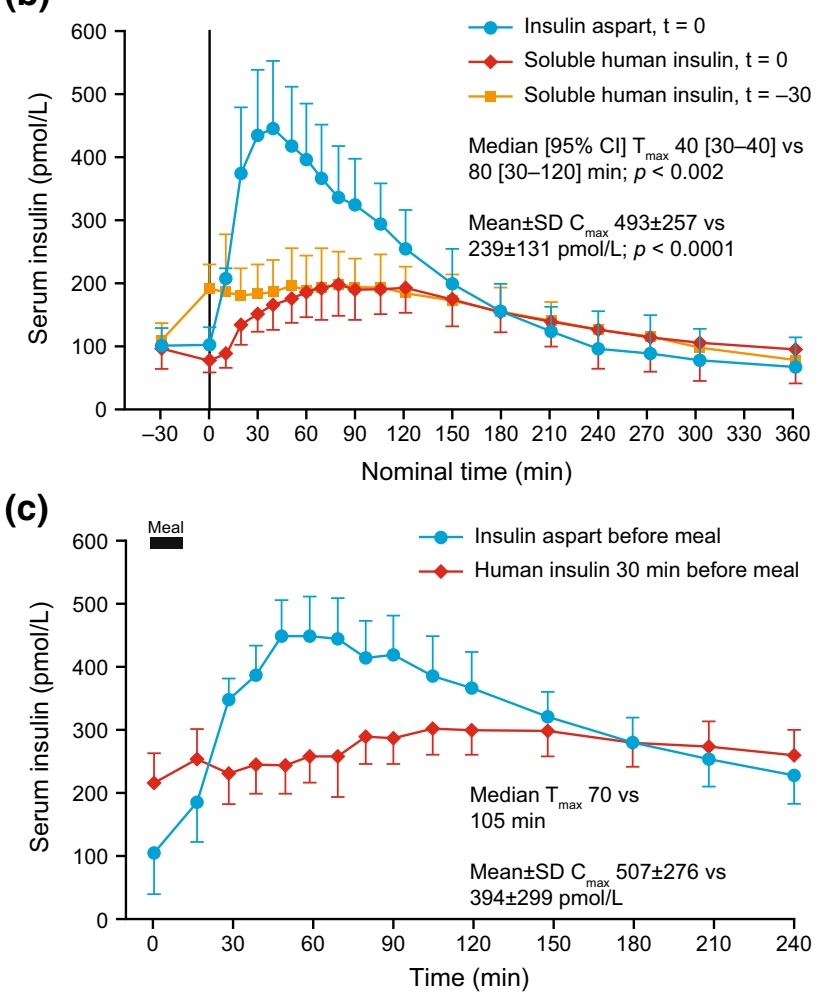

Fig. 1 Pharmacokinetics of insulin aspart compared with soluble/ regular human insulin in a healthy volunteers $(n=19)$, b patients with T1D $(n=22)$ and $\mathbf{c}$ people with T2D $(n=37)$. $C_{\text {max }}$ maximum concentration, $S D$ standard deviation, $t$ time, T1D type 1 diabetes, $T 2 D$ type 2 diabetes, $T_{\max }$ maximum time. a Reproduced with kind permission from Springer Science + Business Media: Home et al. [39]. b Reproduced with permission from American Diabetes Association. Diabetes Care, American Diabetes Association, 1999. Copyright and all rights reserved. Material from this publication has been used with the permission of American Diabetes Association [41]. c Reproduced with permission from Perriello et al. [44], copyright (C) 2005 John Wiley \& Sons, Inc.

glucose clamp, crossover studies, the first in 18 healthy volunteers who received $0.2 \mathrm{U} / \mathrm{kg}$ insulin aspart delivered by each of the two devices [46]. The time to peak insulin concentration was $>50 \%$ shorter with the jet injector $(31 \pm 3$ vs $64 \pm 6 \mathrm{~min}, p<0.0001)$ and peak insulin 
concentrations were significantly increased. The second study was conducted in 24 patients (12 with T1D and 12 with T2D) [47]. The time to peak insulin concentration was also shorter using the jet injector compared with the pen device in patients with diabetes $(51.3 \pm 6.4$ vs $91.9 \pm 10.2$ $\min ; p=0.003)$. The peak insulin concentrations were similar with each method of administration for jet injector and pen device, respectively.

\subsubsection{Comparison with Rapid-Acting Insulins}

There are few head-to-head studies comparing the PK of insulin aspart with other rapid-acting insulin analogs. One randomized, double-blind study in 20 fasting healthy male volunteers compared insulin aspart and insulin lispro following a single SC injection [48]. Consistent with higher serum insulin concentrations, a stronger suppression of C-peptide was observed during the first $80 \mathrm{~min}$ after injection with insulin aspart compared with insulin lispro. This was in contrast to a randomized, single-blind, crossover study in 14 people with T1D [49] that showed similar peak concentrations for insulin aspart and insulin lispro, but more rapid increase and somewhat faster decline with insulin lispro following a standardized meal. A subsequent study in seven C-peptide-negative patients with T1D was conducted in a hospital setting, where they were fed a standardized evening meal and blood glucose (BG) was stabilized overnight with an intravenous (IV) infusion of regular insulin [50]. In that study, free serum insulin concentrations were similar for insulin aspart and insulin lispro, and the PK properties were indistinguishable. Another randomized, double-blind, glucose clamp, crossover trial in 24 patients with T1D showed equivalent PK profiles for insulin aspart and insulin lispro [51].

Insulin aspart and insulin glulisine were compared in a euglycemic clamp study in 12 healthy adult volunteers [52]. Rate of absorption was more rapid for insulin glulisine; however, those results concerning insulin concentrations should be interpreted with caution due to the different assays used. Insulin aspart was also compared with insulin glulisine in 30 insulin-naïve, obese patients with T2D in a randomized crossover study [53]. Subjects received their allocated insulin treatment $2 \mathrm{~min}$ prior to consuming a standardized meal. The peak insulin concentration was highest with insulin glulisine $(p<0.0001)$.

\subsection{Pharmacodynamics (PD)}

\subsubsection{Comparison with Regular Insulin}

The faster absorption and higher peak concentration of insulin aspart compared with RHI results in an improved pharmacodynamic (PD) profile. As demonstrated during several euglycemic clamp studies in healthy subjects, peak glucose infusion rates were significantly higher and occurred significantly earlier with insulin aspart than with RHI (Table 1) [34, 36-38, 40]. Nevertheless, there may be considerable variability in insulin action across patients. In one study of nine healthy volunteers, intra-individual variability in insulin action for both insulin aspart and human insulin was in the range of 10-30\%, even under strictly controlled conditions [54].

In order to examine the effect of high doses of insulin aspart, particularly during the late metabolic period, insulin aspart was compared with RHI using doses of 6,12 , and 24 (I) $\mathrm{U}$ in 16 healthy subjects during a randomized, doubleblind, crossover study [30]. Results showed that insulin aspart had lesser late metabolic action than RHI at 12 and 24 (I) $\mathrm{U}(p<0.05)$. Duration of action was shorter at all three doses $(p<0.01)$, and the early metabolic effect was also stronger for all three doses $(p<0.05)$ compared with RHI.

In patients with T1D, insulin aspart demonstrates improved postprandial glucose lowering compared with RHI. In a crossover study of 22 subjects with T1D, serum glucose excursions were significantly lower with insulin aspart injected immediately before a meal (891 \pm $521 \mathrm{mmol} \times \mathrm{L}^{-1} \times \mathrm{min}^{-1}$ ) compared with RHI administered immediately before eating $(1311 \pm 512 \mathrm{mmol} \times$ $\left.\mathrm{L}^{-1} \times \min ^{-1}, \quad p<0.0001\right)$ or $30 \mathrm{~min}$ before eating $\left(1106 \pm 571 \mathrm{mmol} \times \mathrm{L}^{-1} \times \min ^{-1}, p<0.02\right)$ [41]. In a randomized, crossover study in 19 adults with T1D, both glucose $C_{\max }$ and $\mathrm{AUC}_{0-4} \mathrm{~h}$ were lower for insulin aspart than for RHI following a single standardized test meal (treatment ratio 0.80 [95\% CI 0.63-1.01]; $p<0.05$, and 0.76 [0.63-0.91]; $p<0.05$, respectively) [42].

Insulin aspart has also demonstrated an improved PD profile in people with T2D $[44,55,56]$. In one doubleblind, crossover study, 25 patients with T2D received either insulin aspart immediately before a meal, or RHI administered either $30 \mathrm{~min}$ prior to or immediately before a meal [55]. Postprandial glucose [PPG] excursions, as estimated using the absolute incremental area over baseline $\left(\mathrm{AUC}_{\text {glucose }}\right)$ was lower when insulin aspart was compared with RHI administered at mealtime ( AUC $_{\text {glucose }} 899 \pm 609$ vs $1102 \pm 497 \mathrm{mmol} / \mathrm{L} / \mathrm{min}, p<0.01)$ but there was no difference when RHI was administered $30 \mathrm{~min}$ prior to mealtime ( AUC $\left._{\text {glucose }} 868 \pm 374, p=0.44\right)$. Similarly, $C_{\max }$ glucose was lower for insulin aspart compared with RHI at mealtime $(10.8 \pm 2.2$ vs $12.0 \pm 2.4 \mathrm{mmol} / \mathrm{L}$, $p<0.02$ ), but not different when RHI was administered $30 \mathrm{~min}$ prior to mealtime $(11.1 \pm 1.8 \mathrm{mmol} / \mathrm{L}, p=0.97)$. In another randomized, double-blind, crossover trial, insulin aspart at mealtime was compared with RHI injected 30 min prior to eating [44]. Results indicated that PPG excursions were $20 \%$ lower with insulin aspart (treatment 
Table 1 Pharmacodynamic results from euglycemic clamp studies comparing insulin aspart with RHI in healthy male volunteers

\begin{tabular}{|c|c|c|c|c|}
\hline Study & Number of subjects & Insulin & $\begin{array}{l}\text { Peak glucose infusion } \\
\text { rate }(\mathrm{mg} / \mathrm{min} / \mathrm{kg})^{\mathrm{A}} \pm \mathrm{SD}\end{array}$ & $\begin{array}{l}\text { Time to peak glucose } \\
\text { infusion }(\mathrm{min}) \pm \mathrm{SD}\end{array}$ \\
\hline \multirow[t]{2}{*}{ Heinemann et al. 1993 [36] } & \multirow[t]{2}{*}{14} & Insulin aspart & $12.2 \pm 3.1^{\mathrm{a}}$ & $104 \pm 27^{b}$ \\
\hline & & RHI & $10.6 \pm 2.7$ & $165 \pm 42$ \\
\hline \multirow[t]{2}{*}{ Heinemann et al. 1996 [37] } & \multirow[t]{2}{*}{24} & Insulin aspart & $10.2 \pm 2.3^{\mathrm{c}}$ & $105 \pm 18^{\mathrm{b}}$ \\
\hline & & RHI & $8.4 \pm 2.0$ & $148 \pm 27$ \\
\hline \multirow[t]{2}{*}{ Heinemann et al. 1998 [54] } & \multirow[t]{2}{*}{19} & Insulin aspart & $11.2 \pm 2.8$ & $104 \pm 16$ \\
\hline & & RHI & $9.5 \pm 2.3$ & $156 \pm 29$ \\
\hline \multirow[t]{6}{*}{ Mudaliar et al. 1999 [38] } & \multirow[t]{6}{*}{20} & Insulin aspart $^{B}$ & & $94 \pm 46^{\mathrm{b}}$ \\
\hline & & $\mathrm{RHI}^{\mathrm{B}}$ & & $173 \pm 62$ \\
\hline & & Insulin aspart ${ }^{\mathrm{C}}$ & & $111 \pm 59^{\mathrm{b}}$ \\
\hline & & $\mathrm{RHI}^{\mathrm{C}}$ & & $192 \pm 51$ \\
\hline & & 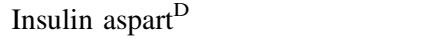 & & $145 \pm 122^{\mathrm{a}}$ \\
\hline & & $\mathrm{RHI}^{\mathrm{D}}$ & & $193 \pm 60$ \\
\hline \multirow[t]{2}{*}{ Engwerda et al. 2011 [46] } & \multirow[t]{2}{*}{18} & Insulin aspart (needle-free device) & $6.49 \pm 0.58$ & $51 \pm 3^{\mathrm{d}}$ \\
\hline & & Insulin aspart (pen) & $6.09 \pm 0.56$ & $105 \pm 11$ \\
\hline
\end{tabular}

GIR glucose infusion rate, $R H I$ regular human insulin, $S D$ standard deviation

${ }^{\mathrm{a}} p<0.05 ;{ }^{\mathrm{b}} p<0.001 ;{ }^{\mathrm{c}} p=0.001 ;{ }^{\mathrm{d}} p<0.0001$, all vs comparator treatment

A After subtraction of mean baseline GIR

${ }^{B}$ Injected into abdomen

C Injected into deltoid

D Injected into thigh

ratio 0.80 [95 \% CI 0.66-0.98]; $p=0.034$ ), with maximum serum glucose levels being similar for the two treatments.

A randomized, placebo-controlled, crossover study examined the effect of a fixed, weight-based dose of insulin aspart on PPG in people with T2D in a real-life setting. Patients followed their typical diet and the effect on glucose fluctuation was evaluated using continuous glucose monitoring (CGM) [57]. A dose of $0.06 \mathrm{U} / \mathrm{kg}$ was chosen based on earlier work (described previously), and insulin aspart was administered $30 \mathrm{~min}$ prior to meals. Over a 24-h period, the duration of $\mathrm{BG}$ values $>8 \mathrm{mmol} / \mathrm{L}$ was shorter for insulin aspart when compared with placebo $(8.1 \pm 1.4$ vs $12.7 \pm 1.3 \mathrm{~h}$, respectively; $p<0.03)$ and the AUC $_{\text {glucose }}>8 \mathrm{mmol} / \mathrm{L}$ was less for insulin aspart than for placebo $(0.6 \pm 0.2 \mathrm{mmol} / \mathrm{L} / \mathrm{h}$ vs $1.2 \pm 0.2 \mathrm{mmol} / \mathrm{L} / \mathrm{h}$, respectively; $p<0.001)$.

With the rationale that postprandial administration might allow for better matching insulin dose to actual carbohydrate intake, CGM in a hospital setting was used to compare PPG excursions with preprandial insulin aspart or postprandial insulin glulisine in 12 patients with T2D, all using insulin glargine once daily at bedtime [56]. Results indicated that multiple daily injections of either insulin aspart ( -10 to $0 \mathrm{~min}$ ) or insulin glulisine (0 to $5 \mathrm{~min}$ ) resulted in similar daily $\mathrm{BG}$ excursions.

\subsubsection{Comparison with Rapid-Acting Analogs}

Head-to-head trials comparing insulin aspart to insulin lispro have generally shown comparable PD [50, 51]. In a randomized, double-blind crossover study in 20 healthy male volunteers, following a single injection of insulin aspart or insulin lispro, plasma glucose concentrations after 50 min were lower using insulin aspart when compared with insulin lispro $(3.2 \pm 0.1$ vs $3.5 \pm 0.1 \mathrm{mmol} / \mathrm{L}$, respectively; $p=0.026$ ) [48]. Blood blucose $t_{\min }$ was $59.3 \pm 3.4 \mathrm{~min}$ and $63.5 \pm 5.3 \mathrm{~min}$, for insulin aspart and insulin lispro, respectively, which was not significantly different.

Insulin aspart and insulin glulisine were compared in a euglycemic clamp study in 12 healthy adult volunteers [52]. The area under the glucose infusion rate curve (AUC GIR $_{0-30 \mathrm{~min}}$ ) indicated a greater early metabolic effect for insulin glulisine $(30.3 \pm 26.4$ vs $16.2 \pm 18.4 \mathrm{mg} / \mathrm{kg}$; $p=0.04)$ and an earlier onset of action as indicated by time to $10 \%$ of $\mathrm{GIR}_{\max }$ (9 vs $17 \mathrm{~min} ; p=0.01$ ), which was consistent with the faster absorption discussed under PK. Insulin aspart was also compared with insulin glulisine in 30 insulin-naïve, obese patients with T2D in a randomized, crossover study [53]. Subjects received their allocated insulin treatment 2 min prior to consuming a standardized meal. The $\mathrm{AUC}_{\text {glucose }}$ during the first hour 
after injection (149 vs $158 \mathrm{mg} * \mathrm{~h} / \mathrm{dL}, p=0.046$ ) as well as maximal glucose concentration $(170$ vs $181 \mathrm{mg} / \mathrm{dL}$, $p=0.03$ ) was significantly lower with insulin glulisine. However, for the total study period of $360 \mathrm{~min}$, plasma glucose concentration and glucose excursions were similar for the two treatments. A randomized, crossover study in 12 patients with T2D was conducted in a hospital setting to compare insulin aspart with insulin glulisine after a single bout of exercise [58]. Both insulins were injected SC immediately before breakfast. One hour after eating, subjects began controlled aerobic exercise on a bicycle. PPG levels were significantly lower in the insulin aspart group at 90,120 , and $150 \mathrm{~min}$ after exercise (all $p<0.05$ ), although the advantage was confined to patients with body mass index $(\mathrm{BMI})<25 \mathrm{~kg} / \mathrm{m}^{2}$.

Finally, the PD findings comparing delivery of insulin aspart using a jet injector versus a pen device mirrored the improved PK findings [46, 47]. Results for the first study in healthy volunteers are shown in Table 1 . In the second study, the glucose clamp technique was used to assess BG levels after a test meal. Jet injection reduced BG levels during the first hour after injection when compared with the pen device $\left(154.3 \pm 20.8\right.$ vs $196.3 \pm 18.4 \mathrm{mmol}^{*} \mathrm{~min}^{*} \mathrm{~L}^{-1}$, respectively; $p=0.041$ ), but there was no difference in BG levels over the next $5 \mathrm{~h}$.

\subsection{PK/PD in Special Populations}

\subsubsection{Elderly Patients}

It is important to determine whether the faster absorption, shorter time to peak activity, and shorter duration of action of insulin aspart compared with RHI observed in younger people are maintained in the elderly, who may be more likely to have compromised renal or hepatic function. In one randomized, double-blind, crossover study, 19 elderly ( $\geq 65$ years) subjects with uncomplicated T2D were given a single injection of insulin aspart or RHI during a euglycemic clamp [59]. Insulin aspart was associated with higher early metabolic activity [AUC ${ }_{\mathrm{GIR}}(0-120 \mathrm{~min})$ (255 \pm 196 vs $110 \pm 68 \mathrm{mg} / \mathrm{kg} ; \quad p<0.0001)$ and $\mathrm{AUC}_{\mathrm{GIR}}(0-300 \mathrm{~min})$ $(931 \pm 584$ vs $677 \pm 407 \mathrm{mg} / \mathrm{kg} ; p=0.0001)]$ and lower late metabolic activity [AUC ${ }_{\text {GIR (300-600 min) }}(353 \pm 188$ vs $683 \pm 372 \mathrm{mg} / \mathrm{kg} ; p=0.0006)]$ compared with RHI. As would be expected, PK parameters such as $C_{\max }, T_{\max }$, and $\mathrm{AUC}_{\text {insulin }(0-60,0-120 \text { and } 0-300 \mathrm{~min})}$ were higher for insulin aspart (all $p<0.01)$.

In 19 patients with T2D (mean age $72 \pm 1$ year), insulin aspart was given immediately prior to a liquid test meal or RHI 30 min prior [60]. Unlike the trial described above, the insulin and glucose profiles were nearly identical for the two insulins.

\subsubsection{Children and Adolescents with Type 1 Diabetes}

The PK/PD properties of insulin aspart are important to evaluate in children, particularly because PPG excursions may be marked, and clinical consequences of hypoglycemia of concern [61]. One randomized, double-blind, crossover study compared insulin aspart and RHI in nine children aged 6-12 years and nine adolescents aged 13-17 years [62]. Insulin aspart demonstrated a significantly shorter time to $C_{\max }$ than RHI [median (interquartile range) $T_{\max }$ ins 40.0 (40-50) $\min$ vs 75.0 (60-120) $\mathrm{min}$, respectively; $p<0.001]$. The maximum insulin concentration was higher for insulin aspart compared with RHI $(p<0.0001)$, and was slightly greater in the older (13-17 years) age group, compared with children aged 6-12 years. With respect to PD, the estimated geometric mean ratio for $\Delta C_{\max }$ insulin aspart/RHI was $0.68[95 \% \mathrm{CI}$ 0.47-0.99]; $p<0.05$. However, $\Delta \mathrm{AUC}_{\text {glucose } 0-4 \mathrm{~h}}$ and $T_{\text {max glucose }}$ were not significantly different.

\subsubsection{In Continuous Subcutaneous Insulin Infusion}

The time to steady-state concentration of insulin aspart in continuous subcutaneous insulin infusion (CSII) was studied in 10 healthy volunteers, 18-31 years of age, with or without an initial SC bolus [63]. The calculated steadystate concentration did not differ with use of an initial SC bolus, although use of a bolus resulted in an initial overshoot of insulin aspart with a significantly higher AUC $(p<0.001)$. There was a non-significant trend towards longer time to steady state using a bolus compared with no bolus (233 vs $166 \mathrm{~min}$, respectively; $p=0.068$ ). Mathematical modeling results suggested that time to achieve steady state concentration could be shortened by administration of a mean bolus of $0.89 \mathrm{U}$, compared with omitting the bolus.

In children, the effect of using a diluted $(20 \mathrm{U} / \mathrm{mL})$ concentration of insulin aspart compared with the standard concentration $(100 \mathrm{U} / \mathrm{mL})$ in CSII was evaluated to determine if dilution could accelerate absorption [61]. In this two-period, crossover study, eleven children aged 3.8-7 years were randomized to either diluted or standard concentrations of insulin aspart. There was no difference in $T_{\max }(p=0.59)$; however, the diluted formulation showed less inter-subject variability compared with the standard formulation (SD 8.7 vs $14.4 \mathrm{~min}$, respectively; $p=0.047$ ). There was also no difference in metabolic clearance of insulin ( $p=0.47)$ and background plasma insulin concentration $(p=0.66)$. Thus, given that the PK of insulin aspart remains unchanged in CSII after fivefold dilution, there may be some advantages in using a diluted solution to dampen variability in absorption for adolescents. 
A retrospective study of 5804 plasma insulin measurements from 70 adults and children treated with CSII examined the reproducibility of insulin aspart PK [64]. There were no differences associated with gender, and $<20 \%$ of intersubject variability in PK parameters was associated with gender, $\mathrm{BMI}$, total daily insulin dose, $\mathrm{HbA}_{1 \mathrm{c}}$, and diabetes duration. Metabolic clearance rate was found to be highly reproducible. Bioavailability of insulin aspart was assessed when administered as SC bolus every hour, via CSII, or via continuous IV infusion [65]. Mean serum insulin aspart concentrations were not significantly different for the three modes of administration $(p=0.17)$ and there was no difference in the $\mathrm{AUC}_{\text {glucose infusion rate }}(p=0.37)$.

One randomized, crossover, euglycemic clamp study that used CSII in 17 adolescents with T1D compared the PD of insulin aspart with insulin lispro [66]. At days 1 and 4, there were no statistically significant differences in $\mathrm{AUC}_{\mathrm{GIR}}, \mathrm{GIR}_{\max }, T_{\max }$ GIR, time to discontinuation of exogenous glucose, time to half-maximal increase of peak action or time to half-maximal decrease from peak action.

\subsubsection{In Obesity and Renal/Hepatic Impairment}

It is important to assess whether obesity, renal and/or hepatic impairment might affect insulin absorption. In one study, several groups of patients were evaluated [67]. This included $23 \mathrm{~T} 1 \mathrm{D}$ patients with BMI values $>19 \mathrm{~kg} / \mathrm{m}^{2}$, another group of 18 patients with T1D and varying degrees of renal function (normal renal function, mild renal impairment, moderate renal impairment, severe renal impairment not yet requiring hemodialysis), and a third group of 24 patients without diabetes but with varying degrees of hepatic impairment. Correlation and regression analyses indicated there were no clinically important relationships between insulin aspart PK and BMI, renal impairment, or hepatic impairment.

Insulin requirements of adult (20-85 years) patients were reported in an observational study of 346 people with T1D including 50 pump users and varying degrees of renal dysfunction determined as the estimated glomerular filtration rate (eGFR) [68]. Consistent with the results of Holmes et al. described above [67], there was no relationship between renal function and the requirments of short-acting insulin. However, results from insulin lispro users $(n=118)$ indicated a significant relationship between dose and eGFR over the measured ranges: subjects with eGFR $<60 \mathrm{~mL} / \mathrm{min}$ required approximately $32.6 \%$ less insulin lispro than those with normal renal function $(p=0.002)$.

\subsubsection{In Pregnancy}

In one short-term crossover study, PK and PD were assessed after a test meal (breakfast) in 15 women with gestational diabetes treated with either no exogenous insulin, RHI, or insulin aspart [69]. The mean \pm SE peak insulin concentration was significantly lower during the meal in which no exogenous insulin was administered $(72.6 \pm 9.7 \mu \mathrm{U} / \mathrm{mL})$ than with either regular insulin $(84.7 \pm 10.8 \mu \mathrm{U} / \mathrm{mL} ; p=0.034$, compared with no insulin) or insulin aspart $(95.9 \pm 10.9 \mu \mathrm{U} / \mathrm{mL} ; p=0.009)$. $\mathrm{AUC}_{\text {glucose }}$ at 120,180 , and $240 \mathrm{~min}$ was not significantly different when comparing RHI with no exogenous insulin, but $\mathrm{AUC}_{\text {glucose }}$ for insulin aspart was lower compared with no insulin $(p=0.018$ and $p=0.005$, for 180 and $240 \mathrm{~min}$, respectively).

\section{Clinical Efficacy of Insulin Aspart}

As summarized in Table 2, numerous randomized trials as well as observational studies have been published describing the use of insulin aspart in basal-bolus regimens in patients with T1D and T2D, use with oral antidiabetic medications in T2D, or use with basal insulin used as needed in T2D. There are also numerous studies reporting efficacy of insulin aspart in CSII in comparison with RHI as well as other rapid-acting analogs (described in Table 3 and discussed separately). Studies done with the primary goal of comparing different basal insulins (e.g., insulin degludec vs insulin glargine) and in which insulin aspart was used in both trial arms are not discussed here.

\subsection{Patients with Type 1 Diabetes (T1D)}

In studies in adult patients with T1D, in which insulin aspart was used in basal-bolus regimens and where both trial arms used neutral protamine Hagedorn (NPH) as the basal insulin, insulin aspart demonstrated improved PPG control compared with RHI after breakfast, lunch, and dinner [70-72], after breakfast and dinner [75], or after lunch and dinner [73] (Table 2a). In studies from 12 weeks to 3 years in duration, $\mathrm{HbA}_{1 \mathrm{c}}$ was significantly lower in patients using insulin aspart compared with RHI [70, 71, 74, 75] (Table 2a). In three other trials involving adults, one of 8 weeks [76], one of 16 weeks [77] and one of 64 weeks [72], end-of-trial $\mathrm{HbA}_{1 \mathrm{c}}$ was comparable in both treatment arms. End-of-trial $\mathrm{HbA}_{1 \mathrm{c}}$ was significantly lower with insulin aspart in one 18-week study in which an all-analog regimen (insulin aspart + insulin detemir) was compared with RHI + NPH [78]. Results for adolescents are discussed in a later section, as are results using CSII.

\subsection{Patients with Type 2 Diabetes (T2D)}

Studies using insulin aspart in patients with T2D are summarized in Table $2 \mathrm{~b}$. As these data demonstrate, 


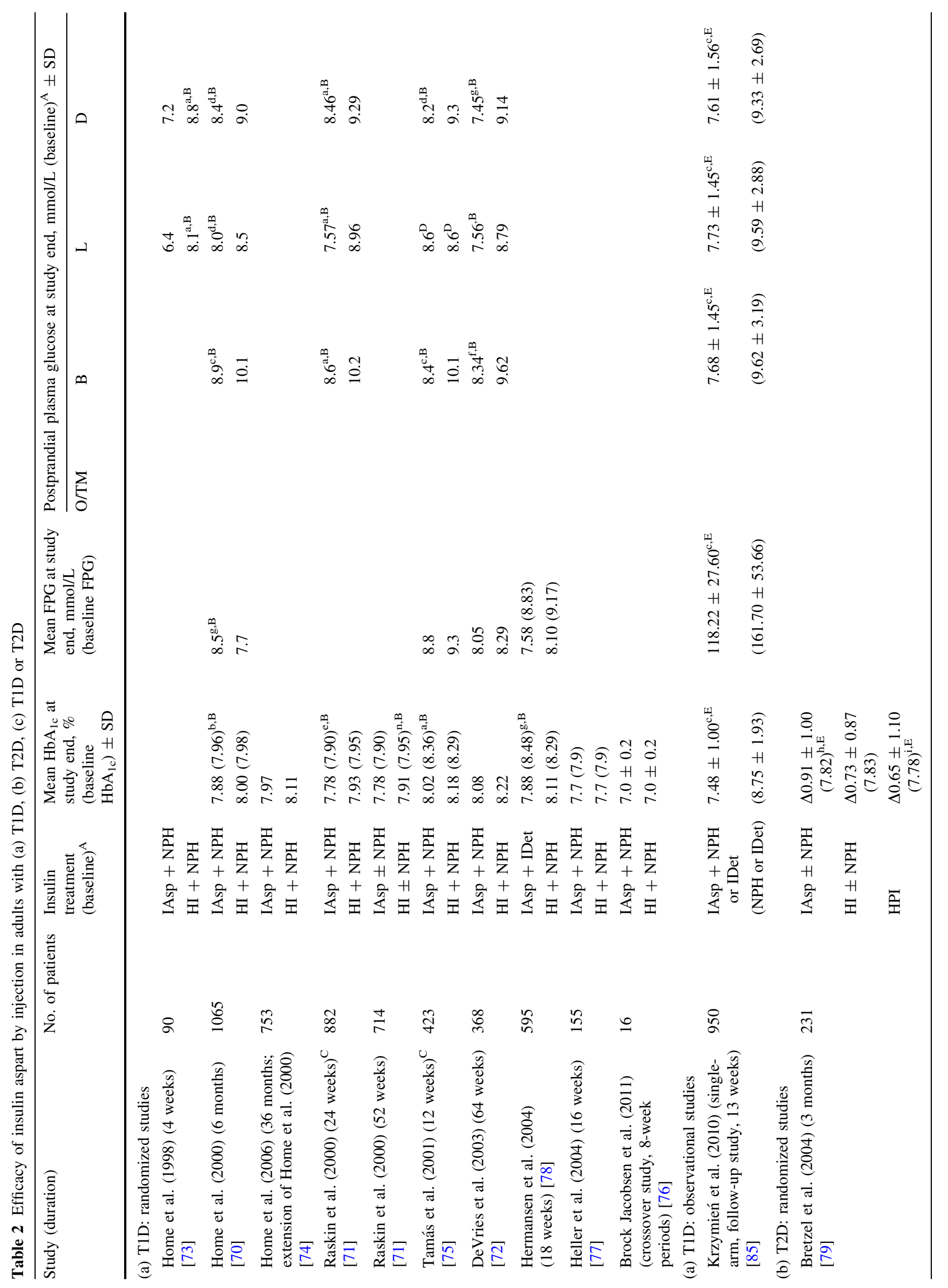




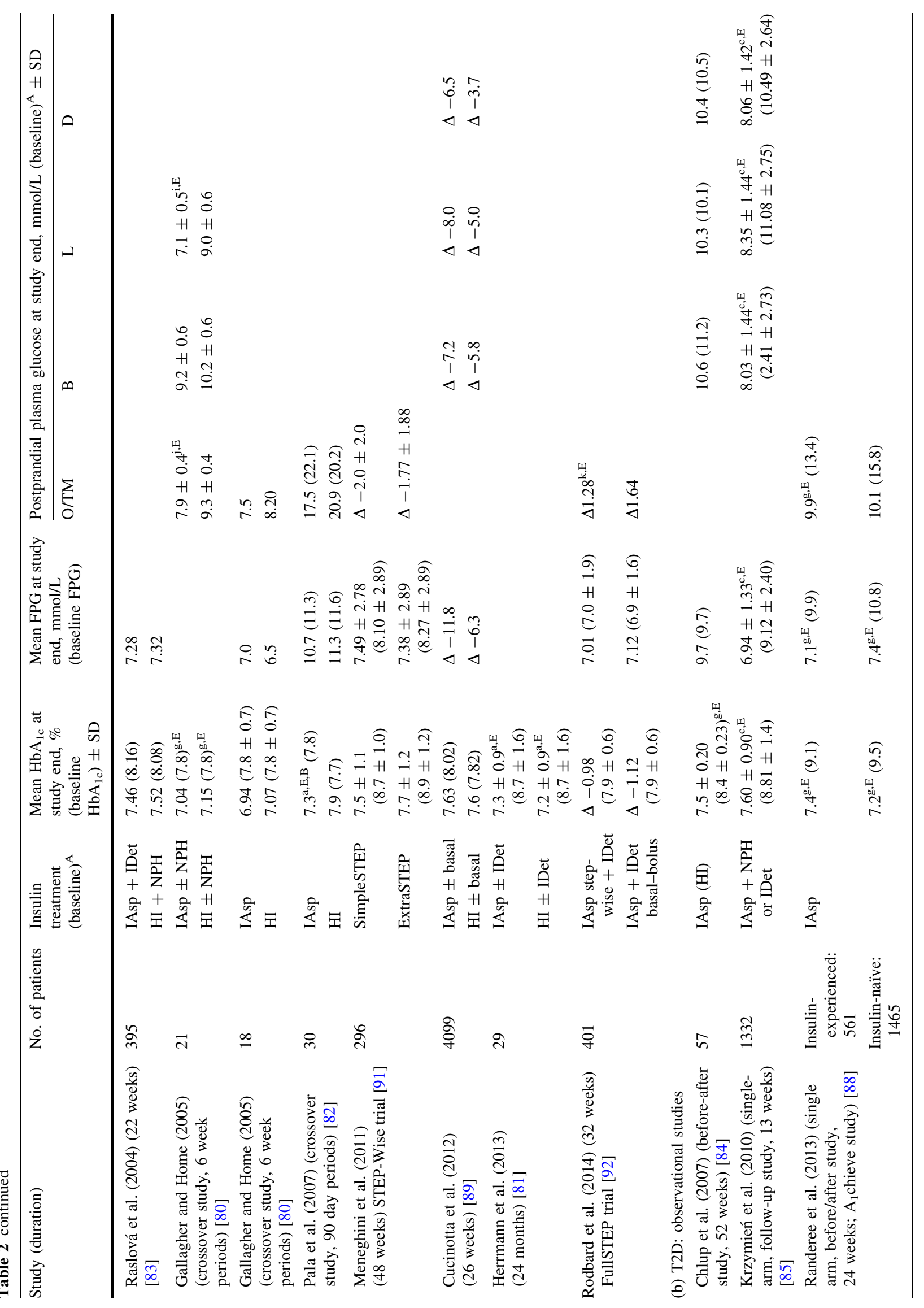


50

K. Hermansen et al.

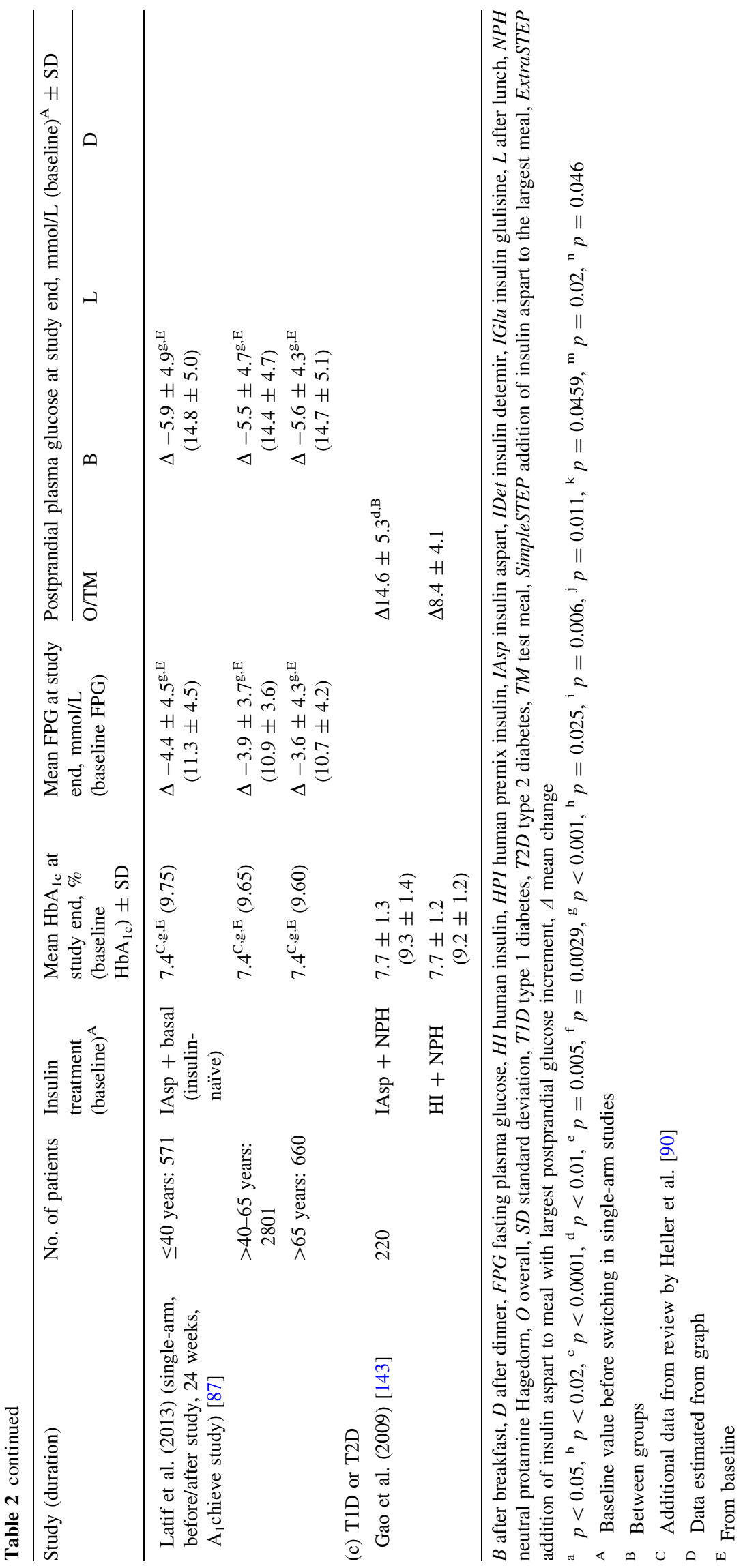

$\Lambda$ Adis 


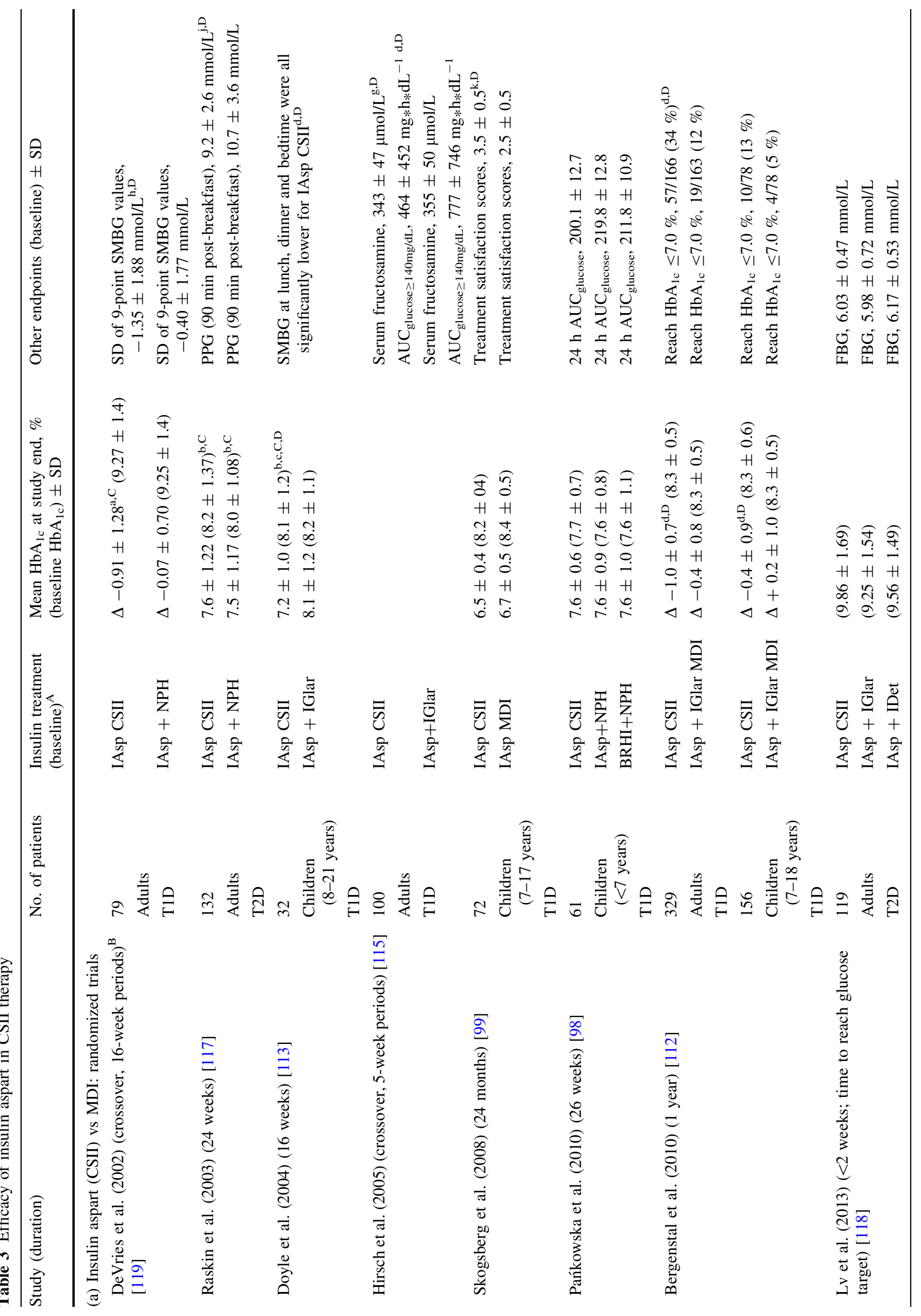




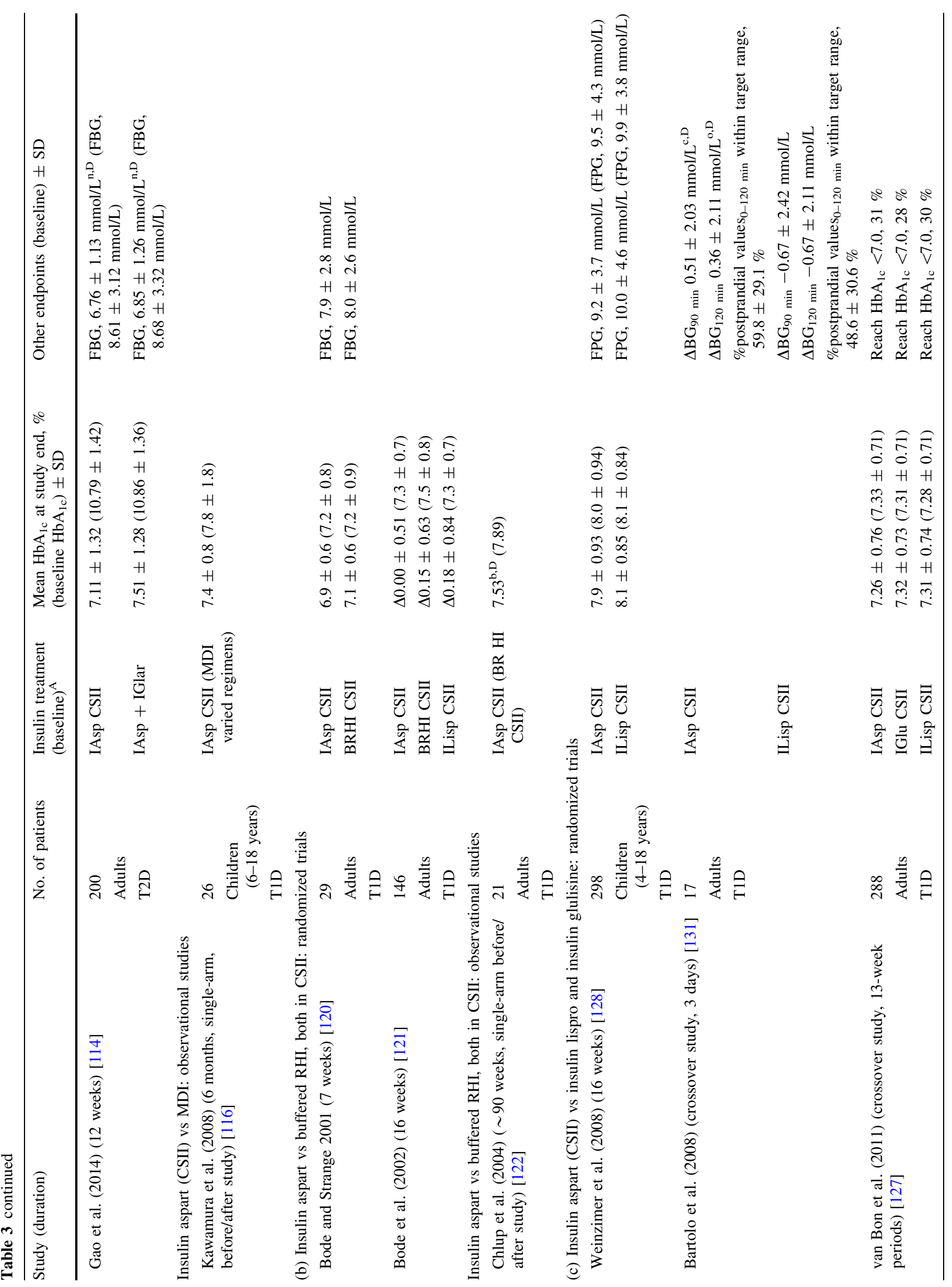




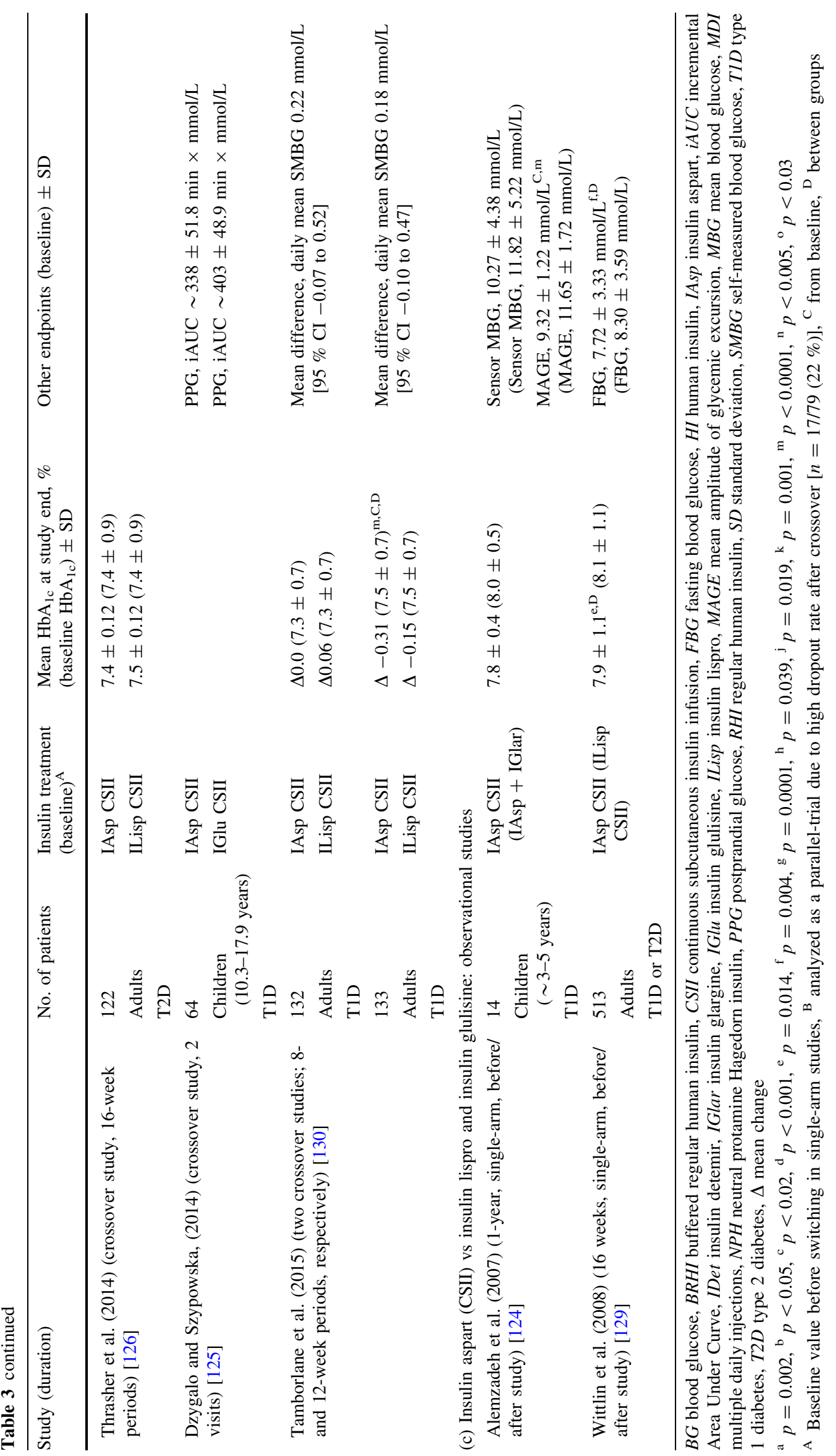


insulin aspart decreased $\mathrm{HbA}_{1 \mathrm{c}}$ from baseline in five randomized studies [79-83]. $\mathrm{HbA}_{1 \mathrm{c}}$ was also reduced in one 52-week study [84] and in one 13-week study in which patients switched from RHI to insulin aspart [85]. In another randomized study, baseline and end-of-trial $\mathrm{HbA}_{1 \mathrm{c}}$ remained similar for both insulin aspart and RHI [86].

In two large observational studies, $\mathrm{HbA}_{1 \mathrm{c}}$, PPG and fasting plasma glucose (FPG) levels were significantly reduced after switching to insulin aspart, one in which patients used insulin aspart with a basal insulin [87], and another in which basal insulin was not used [88]. In both studies, oral antidiabetic drugs (OADs) were allowed. In a third large observational study comparing insulin aspart with RHI (use of basal insulin was optional), $\mathrm{HbA}_{1 \mathrm{c}}$ was decreased from baseline in both groups $(p<0.0001)$. FPG and PPG values after each meal were also reduced from baseline in both groups ( $p \leq 0.05$ for most comparisons) [89].

\subsection{Meta-Analysis in T1D and T2D}

A meta-analysis of ten published and unpublished randomized trials of basal-bolus therapy in T1D and T2D with a minimum duration of 12 weeks has further confirmed significantly better glucose control with insulin aspart treatment compared with RHI (mean overall difference between treatments in $\mathrm{HbA}_{1 \mathrm{c}}-0.1 \%$ [95\% CI -0.15 to $-0.04] ; p<0.001$, favoring insulin aspart) [90]. PPG was significantly lower after treatment with insulin aspart compared with RHI, but the analysis did present a significant level of heterogeneity $(p<0.001)$.

\subsection{Intensification of Treatment with Insulin Aspart}

\subsubsection{Intensification with All-Analog Regimens}

Due to the inevitable decline in $\beta$-cell function characterizing T2D, patients typically require progressive intensification of therapy when diet, exercise, and metformin cannot maintain adequate glycemic control. Typically, this begins with adding a second $\mathrm{OAD}$, drugs of the incretin class, a basal insulin or a premixed insulin. Eventually many patients require full basal-bolus regimens to ensure adequate prandial coverage and acceptable overall glucose control [16]. Basal-bolus regimens comparing insulin aspart with RHI in T1D or T2D have been discussed above. Trials have also compared all-analog regimens with RHI regimens. For example, one 18-week trial compared insulin aspart with insulin detemir versus RHI in combination with NPH [78]. Results demonstrated a lower $\mathrm{HbA}_{1 \mathrm{c}}$ in the arm using an all-analog regimen $\left(\mathrm{HbA}_{1 \mathrm{c}} 7.88 \%\right.$ vs $8.11 \%$; mean difference $-0.22 \%$ point $[95 \% \mathrm{CI}-0.34$ to -0.10 ]; $p<0.001$ ), indicating that insulin aspart could be used effectively with a basal insulin analog in a full basal-bolus regimen.

\subsubsection{Step-Wise Addition of Insulin Aspart}

A full basal-bolus regimen may be intimidating for patients with T2D due to the complexity of these regimens and risk of hypoglycemia. Therefore, some patients may initially intensify treatment by using a premixed insulin to improve prandial coverage. Another option that has been examined is the step-wise addition of insulin aspart injections to basal insulin. Two trials have demonstrated the efficacy and feasibility of this approach [91, 92]. The first was a randomized, controlled, parallel-group trial of 48 weeks' duration in which 296 patients with T2D already using basal insulin were randomized to either the SimpleSTEP regimen (addition of insulin aspart at the anticipated largest meal of the day; $n=150$ ) or the ExtraSTEP regimen (addition of insulin aspart with the meal having the highest measured increase in postprandial glucose; $n=146$ ) [91]. Both groups administered insulin detemir once daily at bedtime. $\mathrm{HbA}_{1 \mathrm{c}}$ decreased by about $1.2 \%$ in both groups, and the strategies were equally effective at lowering $\mathrm{HbA}_{1 \mathrm{c}}$ (treatment difference $-0.06 \%$ [95 \% CI -0.29 to 0.17$])$. Insulin aspart dose was identical in each $\operatorname{arm}(0.53 \mathrm{U} / \mathrm{kg})$. The decrease in PPG increment was similar in both groups, suggesting that the sequential addition of prandial insulin aspart to one or more meals improves glycemic control in those who need intensification beyond basal insulin (Table $2 b$ ).

The FullSTEP trial was a phase IV, 32-week, randomized, parallel-group, treat-to-target, non-inferiority trial that compared a full basal-bolus regimen to a step-wise approach [92]. A total of 401 patients with T2D, from 150 sites in seven nations, participated. Those in the full basalbolus group administered insulin aspart before each main meal, whereas those in the step-wise group added insulin aspart first to the largest meal and, if $\mathrm{HbA}_{1 \mathrm{c}} \geq 7.0 \%$, added additional boluses at the next largest meal at week 11 and week 22. Both groups used insulin detemir once daily at bedtime as the basal insulin. $\mathrm{HbA}_{1 \mathrm{c}}$ and FPG decreased by similar amounts in both groups, but the mean prandial glucose increment was significantly higher for the stepwise group (treatment difference, $0.36 \mathrm{mmol} / \mathrm{L}[95 \% \mathrm{CI}$ 0.01-0.71]; $p=0.046$ ) (Table 2b).

\subsection{Long-Term Microvascular and Macrovascular Complications}

A desirable long-term outcome of better glucose control would be a reduced risk of adverse CVD outcomes, although as multiple reviews have discussed, it has been difficult to demonstrate this unequivocally in large trials 
[10, 12-15, 25]. One large observational study using computerized data from patients with T2D in the German Disease Analyzer database (3154 patients using insulin aspart and 3154 patients using RHI) examined several key cardiovascular outcomes [93]. After a mean follow-up of 3.5 years, patients using insulin aspart had a $15 \%$ lower risk of combined macrovascular outcomes (hazard ratio 0.85 [95 \% CI 0.75-0.96]), a $42 \%$ lower risk of stroke or transient ischemic attack $(0.58$ [0.45-0.74]); a $31 \%$ lower risk of myocardial infarction (0.69 [0.54-0.88]), a $16 \%$ lower risk of coronary heart disease (0.84 [0.72-0.94], and a $20 \%$ lower risk of peripheral vascular disease $(0.80$ [0.69-0.93]), (all $p<0.05$ ) compared with those using RHI. The risk of microvascular complications was not significantly different for users of insulin aspart and RHI (0.96 [0.87-1.06]).

Oxidative stress due to increased glucose fluctuations has been proposed as one possible reason for an association between PPG levels and CVD, but a small $(n=43)$ trial comparing thrice-daily insulin aspart versus once-daily insulin detemir showed significantly lower measures of oxidative stress, based on urinary 8-iso-prostaglandin F2 $\alpha$ only in the insulin detemir group $(p=0.0079)$ [94]. The absence of a uniformly accepted standard of how to estimate the postprandial hyperglycemia and glycemic variability adds a further challenge to this debate [25].

\subsection{Special Populations}

\subsubsection{Children and Adolescents}

Control of PPG may be particularly difficult in children, in part due to the high carbohydrate content of breakfast cereals. Postprandial administration theoretically offers a better opportunity for matching insulin dose to the actual meal content. The effect of preprandial (immediately before meal start) compared with postprandial (up to 30 min after start of meal) administration of insulin aspart was evaluated using a randomized, crossover trial design in 76 children and adolescents with T1D aged 6-17 years [95]. With respect to 7-point BG profiles, the treatment difference for pre- to post-comparison was statistically significant at 120 min post-breakfast. In a similar 12-week crossover study in 26 children with T1D, RHI injected 30 min before mealtime was compared with insulin aspart injected at or shortly after meals [96]. The average postprandial increment was similar for both insulins.

Insulin aspart was compared with insulin glulisine in 13 children with T1D, aged 5.4-11.8 years and using multiinjection therapy [97]. Results indicated that use of insulin aspart was associated with a lower postprandial glucose excursion at $2 \mathrm{~h}(+98.6 \pm 66.9 \mathrm{vs}+113.5 \pm 65.2 \mathrm{mg} / \mathrm{dL}$, $p=0.01)$ and $\mathrm{BG}$ was lower with insulin aspart even at
$4 \mathrm{~h}(129.0 \pm 37.0$ vs $141.9 \pm 36.5 \mathrm{mg} / \mathrm{dL}, p=0.04)$ after breakfast. In a 26-week, randomized, parallel-group trial in 61 children with T1D, participants were randomized to either insulin aspart multiple daily injection (MDI) or RHI MDI, each with NPH as the basal insulin, or to insulin aspart CSII [98]. After 26 weeks, mean $\mathrm{HbA}_{1 \mathrm{c}}$ remained essentially unchanged from baseline and comparable in each of the three groups.

In a randomized, parallel-group trial in 72 children and adolescents aged 7-17 years with T1D, insulin aspart MDI with NPH as the basal insulin $(n=38)$ was compared with insulin aspart CSII $(n=34)$ [99]. After 24 months, there was no difference in $\mathrm{HbA}_{1 \mathrm{c}}$ between the groups $(p=0.33)$. Basal-bolus regimens of either insulin aspart + insulin glargine or RHI + NPH were compared after 24 weeks of treatment in a randomized, parallel-group study of 40 children $6-10$ years of age [100]. At end of trial, $\mathrm{HbA}_{1 \mathrm{c}}$ and FBG were similar in both treatment groups.

The effect of pre-meal insulin treatment with insulin aspart was studied in 30 prepubertal children with T1D using insulin glargine as their basal insulin [101]. Children were randomized to either insulin aspart 2 min before meals or RHI 30 min prior to eating, with the dose estimated using carbohydrate counting; children in the insulin aspart group also received an additional injection before the afternoon snack. At 18 weeks, mean daily BG, glucose variability, and decrease from baseline were similar in both groups. FBG decreased more with RHI $(p=0.012)$ and $\mathrm{HbA}_{1 \mathrm{c}}$ decreased from baseline with RHI but not with insulin aspart $(p=0.018)$.

\subsubsection{Pregnancy}

Pregnant women with diabetes are at risk of adverse maternal and perinatal outcomes [102], which can be mitigated with improved glucose control [103]. In one study, 322 women with T1D on basal-bolus therapy were randomized to either insulin aspart $(n=157)$ or RHI $(n=165)$ as the bolus insulin, with NPH as basal insulin [104]. Change in $\mathrm{HbA}_{1 \mathrm{c}}$ with insulin aspart was non-inferior to RHI. However, the mean prandial glucose increment was lower after each main meal with insulin aspart, with the treatment differences being $-0.75 \mathrm{mmol} / \mathrm{L}[95 \% \mathrm{CI}$ -1.25 to -0.25 ]; $p=0.003$ at 12 weeks' gestation and $-0.40 \mathrm{mmol} / \mathrm{L}[95 \% \mathrm{CI}-0.80$ to -0.01$] ; p=0.044$ at 36 weeks' gestation.

One randomized, parallel-group trial compared the efficacy of insulin aspart with RHI in basal-bolus therapy in 27 women with gestational diabetes [105]. Women were followed from the time of diagnosis (18-28 weeks) to 6 weeks postpartum. Glycemic control was good and comparable with both insulins during the study period $\left(\mathrm{HbA}_{1 \mathrm{c}} \leq 6.0 \%\right)$. However, change from baseline values 
for average PG was greater for insulin aspart when compared with RHI $(-1.09 \pm 0.54$ vs $-0.54 \pm 0.74 \mathrm{mmol} / \mathrm{L}$, respectively; $p=0.003)$.

\subsubsection{Hospitalized Patients}

Consensus guidelines stress the importance of insulinbased treatment for most hospitalized patients with hyperglycemia [106]. Hospitalized patients may have sought emergency care due to diabetic ketoacidosis (DKA), may have been admitted for reasons primarily unrelated to pre-existing diabetes but develop hyperglycemia, or may have been non-diabetic and developed hyperglycemia. Intravenous insulin therapy is often preferred for these patients because it allows rapid adjustment and avoids any problems with absorption due to conditions such as edema or poor perfusion. However, SC administration is less complicated and thus may have advantages for patients in non-intensive care unit (ICU) settings whose BG is not changing rapidly $[107,108]$.

Observational data from a large $(n=3024)$ group of hospitalized patients (67\% ICU) demonstrated the efficacy of using IV insulin aspart, with mean BG decreasing from 19.8 to $8.6 \mathrm{mmol} / \mathrm{L}$ after treatment [109]. Results were similar in ICU and non-ICU patients.

One randomized study examined the efficacy of insulin aspart given either SC every hour $(n=15)$ or every $2 \mathrm{~h}(n=15)$, compared with an IV infusion of RHI $(n=15)$ in consecutive patients admitted for treatment of uncomplicated DKA [107]. Mean duration of treatment until correction of hyperglycemia was similar for all three treatments, indicating that insulin aspart administered SC either hourly or every $2 \mathrm{~h}$ was an effective alternative to IV administration of RHI.

In another study, emergency department (ED) patients with a history of T2D and a $\mathrm{BG} \geq 200 \mathrm{mg} / \mathrm{dL}$ at presentation were randomized to either insulin aspart every $2 \mathrm{~h}$ $\mathrm{SC}$ when $\mathrm{BG}>200 \mathrm{mg} / \mathrm{dL}(n=87)$, or usual care (which could include insulin) per hospital physicians' treatment $(n=89)$ [110]. If subsequently admitted, patients in the intervention group began basal-bolus therapy with insulin detemir. Patients with DKA were excluded from the study. The mean final ED BG was lower in the intervention group when compared with the usual care group $(217 \pm 71$ vs $257 \pm 89 \mathrm{mg} / \mathrm{dL}$, respectively; $p<0.01$ ). The mean length of stay in the ED was also similar in both groups. Among patients assigned to usual care who were eventually admitted, most still received insulin $(76.9 \%$ basal insulin and $70.4 \%$ bolus). Patient-day-weighted mean glucose was lower for the intervention group $(163 \pm 39$ vs $202 \pm 39 \mathrm{mg} / \mathrm{dL}$ for intensive vs usual-care patients, respectively, $p<0.01$ ).
Finally, in a study of 130 nonsurgical patients with T2D and BG between $140-400 \mathrm{mg} / \mathrm{dL}$, patients were randomized to basal-bolus therapy either with insulin aspart at mealtimes + insulin detemir $(n=67)$ or RHI (twice daily $)+\mathrm{NPH}(n=63)$ [111]. Mean BG was similar at baseline in each group, and after 1 day, improved similarly in both groups $(p=0.80)$.

\subsection{Insulin Aspart in Continuous Subcutaneous Insulin Infusion (CSII)}

\subsubsection{Insulin Aspart CSII Versus Multiple Daily Injection (MDI)}

Several studies in adults and children, and in T1D and T2D, have examined glucose control with insulin aspart used in CSII versus other insulins used in MDI [98, 99, 112-119]. Results are presented in Table 3a. The largest trial studied both children $(n=156)$ and adults $(n=329)$ with T1D for 1 year, and reported significantly greater improvements in $\mathrm{HbA}_{1 \mathrm{c}}$ for patients switching to insulin aspart CSII than patients who remained on MDI therapy with insulin aspart concomitant with insulin glargine [112]. One 16-week trial in 32 youths with T1D demonstrated significant improvement from baseline for insulin aspart CSII as well as significantly lower $\mathrm{HbA}_{1 \mathrm{c}}$ compared with MDI therapy [113]. The study by Hirsch et al. demonstrated statistically significant differences in serum fructosamine or $\mathrm{AUC}_{\text {glucose }} \geq 140 \mathrm{mg} / \mathrm{dL}$ with insulin aspart CSII versus MDI [115]. However, other studies have not demonstrated significant improvements in glucose control compared with baseline for insulin aspart CSII or MDI therapy $[99,114,117]$.

\subsubsection{Insulin Aspart Compared with Buffered Regular Human Insulin (RHI), Both in CSII}

Three studies have compared insulin aspart CSII with buffered RHI CSII, using change in $\mathrm{HbA}_{1 \mathrm{c}}$ as the outcome [120-122] (Table 3b). Randomized trials of 7 weeks in 29 adults with T1D [120] and 16 weeks in 146 adults with T1D [121] demonstrated little change in $\mathrm{HbA}_{1 \mathrm{c}}$ from baseline and no between-treatment differences. In contrast, a 90-week study of 21 adults with T1D demonstrated an improvement in $\mathrm{HbA}_{1 \mathrm{c}}$ after switching from buffered RHI to treatment with insulin aspart CSII $(7.89 \%$ vs $7.53 \%$, respectively, $p<0.05$ ) [122].

Another study highlighted differences in glucose control with insulin aspart compared with buffered RHI in 21 Chinese patients with T1D or T2D [123]. The study demonstrated better BG profiles with insulin aspart overall $(p<0.01)$ as well as before breakfast $(6.72 \pm 1.24$ vs 
$7.84 \pm 1.58 \mathrm{mmol} / \mathrm{L}, p=0.01)$, after breakfast $(8.96 \pm$ $2.41 \mathrm{vs} 11.70 \pm 3.11 \mathrm{mmol} / \mathrm{L}, p=0.003)$ and after dinner $(8.15 \pm 2.10$ vs $10.07 \pm 2.36 \mathrm{mmol} / \mathrm{L}, p=0.008)$.

\subsubsection{Insulin Aspart Compared with Other Rapid-Acting Analogs in CSII}

Comparisons of insulin aspart with other analogs in CSII have generally shown no significant differences in $\mathrm{HbA}_{1 \mathrm{c}}$ between treatment groups (Table 3) [124-128]. However, one 16-week, single-arm, before-and-after study in 513 adults with T1D or T2D reported a small but statistically significant decrease in both mean $( \pm \mathrm{SD})$ difference in $\mathrm{HbA}_{1 \mathrm{c}} \quad(-0.1 \pm 0.7 \%, \quad p=0.014) \quad$ and $\mathrm{FBG}$ $(-12.2 \pm 81.0 \mathrm{mg} / \mathrm{dL}, p=0.004)$ after switching from insulin lispro CSII to insulin aspart CSII [129]. Two 24-week, randomized, crossover trials were conducted in subjects with T1D to determine whether glycemic control on day 6 of pump reservoir use of insulin lispro was noninferior to insulin aspart. Insulin lispro did not achieve noninferiority to insulin aspart on day 6 of reservoir usage. In one of the studies, greater decrease in $\mathrm{HbA}_{1 \mathrm{c}}$ with insulin aspart compared with insulin lispro was noted $(p<0.001)$. Insulin aspart mean self-measured blood glucose (SMBG) profiles were lower than the profiles for insulin lispro in both studies; however, daily mean SMBG was not different for the two insulins [130] (Table 3). In a 3-day, randomized, crossover trial in 17 patients with T1D, CGM was used to assess the combined postprandial control after standardized meals. For breakfast and lunch combined, mean changes in BG values were lower for insulin lispro than for insulin aspart at 90 and $120 \mathrm{~min}$ [131] (Table 3).

\subsection{Flexible Dosing}

RHI is typically administered 30 min prior to meals in order to match maximal glucose-lowering action with glycemic load. Pre-meal administration can be inconvenient for patients and also make it difficult to accurately match insulin dose to the anticipated carbohydrate intake. The question of whether injecting closer to or immediately after starting a meal might be equally efficacious was investigated in a randomized, double-blind, crossover trial in 20 patients with T1D in a hospital setting [132]. During each period, one of four treatment combinations was administered: insulin aspart at meal $\left(\mathrm{IAsp}_{0} \mathrm{~min}\right)$ or at 15 min after the meal began ( $\mathrm{IAsp}_{+15 \mathrm{~min}}$ ), and RHI at start of meal $\left(\mathrm{HI}_{0 \mathrm{~min}}\right)$ and at 15 min prior to the meal start $\left(\mathrm{HI}_{-15 \mathrm{~min}}\right)$. PG excursions from baseline levels were highest with RHI given at mealtime $(17.9 \mathrm{mmol} / \mathrm{L} / \mathrm{h})$ compared with other times of administration (13.6, 11.9, and $14.2 \mathrm{mmol} / \mathrm{L} / \mathrm{h}$, for $\mathrm{HI}_{-15 \mathrm{~min},} \mathrm{IAsp}_{0 \mathrm{~min}}$ and $\mathrm{IAsp}_{+15 \mathrm{~min}}$, respectively; all $p<0.05$ vs RHI given at mealtimes). The PG excursions for other administration times were not significantly different from each other. In another crossover study, the effect of administering insulin aspart 30,15 , and 0 min prior to starting a meal was examined in ten patients with T1D on three different study days [133]. Each patient's insulin pump was used to deliver the required prandial bolus, and CGM was used to monitor BG. Administration at -15 min resulted in a significantly lower glucose excursion $(4.77 \pm 0.52$ $\mathrm{mmol} / \mathrm{L})$ than at $0 \min (6.93 \pm 0.76 \mathrm{mmol} / \mathrm{L}, p=0.022)$ and at $-30 \min (6.48 \pm 0.76 \mathrm{mmol} / \mathrm{L}, p=0.025)$.

\subsection{Quality of Life/Treatment Satisfaction with Insulin Aspart}

Studies have evaluated quality of life (QoL) and/or treatment satisfaction using insulin aspart in children [98], adults with T1D [134], and adults with T1D or T2D using CSII [129]. In the pediatric study comparing insulin aspart CSII, insulin aspart MDI, and RHI MDI, both groups randomized to insulin aspart indicated an increase in treatment satisfaction, with the greatest increase being for insulin aspart CSII [98]. In a 6-month, randomized trial, treatment satisfaction was compared in 424 patients with T1D, 283 using insulin aspart MDI and 141 using RHI, with each group using NPH for the basal component [134]. At end of trial, treatment satisfaction on two different validated scales was higher with insulin aspart $(p<0.01)$, mainly due to increased dietary and leisure time flexibility $(p<0.0001)$. QoL was improved with respect to diet restrictions $(p<0.01)$. Finally, in a 16 -week, open-label, multicenter study, 513 adults ( $\geq 18$ years) with T1D or T2D previously using insulin lispro CSII were switched to insulin aspart CSII [129]. Average overall treatment satisfaction scores (Diabetes Treatment Satisfaction Questionnaire, DTSQ) for the two insulins were not significantly different. However, the average overall score on the Insulin Treatment Satisfaction Questionnaire (ITSQ) was significantly greater for insulin aspart than for insulin lispro (treatment difference $1.7 ; p=0.001$ ).

\section{Safety and Tolerability of Insulin Aspart}

\subsection{General Adverse Event Profile}

\subsubsection{Receptor Binding and Mitogenicity}

Insulin and insulin-like growth factor (IGF)-1 binding properties are important to evaluate with any new insulin to ensure that the safety profile is not adversely affected by the molecular modifications introduced during the bioengineering process [135]. Insulin aspart was one of 
several insulin formulations evaluated in an in-vitro study. In that study, insulin aspart was shown to be equipotent to RHI in binding to the insulin receptor [135]. Insulin aspart also dissociated from the insulin receptor at a rate similar to RHI, and had a similar metabolic potency. Furthermore, evaluation of mitogenic potency using human osteosarcoma cells indicated that insulin aspart was slightly less mitogenic than RHI [135].

The effect of insulin aspart, RHI, and two biphasic insulin aspart formulations on the circulating IGF system was studied in vivo in 19 patients [136]. Despite differences in glucose-lowering profiles after a single SC injection, insulin aspart and RHI demonstrated parallel decreases in IGF-binding protein (IGFBP)-1 levels during the first $3 \mathrm{~h}$, and had similar profiles and AUCs for total IGF-1, IGFBP-2, and IGFBP-3. There were minor and clinically unimportant differences in IGFBP-1 during the later part of the study (6-9 h) between insulin aspart and RHI. Neither insulin changed total serum IGF-1 from baseline. Another in vivo evaluation of insulin-like growth factors was done as part of a randomized, two-period ( 8 weeks) crossover study in 16 patients with T1D treated with either insulin aspart + NPH or RHI + NPH [76]. Results indicated no statistically significant differences between treatment groups in total IGF-I, free IGF-I, total IGF-II, IGFBP-1 or IGFBP-2.

\subsubsection{Anti-Insulin Antibodies}

Development of antibodies to SC administered insulin is common, and although they usually are not associated with clinical symptoms [137], there is a hypothetical concern that modifications to the insulin molecule could increase antigenicity and that anti-insulin antibodies could alter PK and/or PD properties. Antibodies of interest would include those specific to RHI or insulin aspart, as well as crossreactive antibodies [138]. These were measured in a variety of patient populations: adults with T1D or T2D [71, 138]; pregnant women with T1D [139]; adults with T2D [137]; children with T1D [138], and women with gestational diabetes [105], all discussed below.

In one study of adults with T1D or T2D, insulin antibody results were combined from three trials, for a total of 1396 patients randomized to insulin aspart and 740 to RHI, with NPH as the basal component [138]. Insulin aspartspecific and RHI-specific antibody levels remained undetectable in most patients throughout the studies. Most patients had cross-reacting antibodies at baseline, which transiently increased with insulin aspart treatment; there were no adverse clinical effects that could be linked to antibody levels. There was also no correlation with absolute levels of antibodies and clinical efficacy or glucodynamic parameters. Increased antibody levels were not associated with an increased insulin dose, and in one case, there was an inverse relationship. Additional detail was obtained from the full publication of a study of patients with T1D (whose data also contributed to the combined analysis by Lindholm et al. [138], discussed previously) [71]. In that group, 882 patients enrolled in the study for 6 months ( $n=596$ for insulin aspart and $n=286$ for RHI) with 714 being followed up to 12 months. Throughout the trial, insulin aspart-specific antibodies remained low (1\% binding). Primarily due to a spike in cross-reacting antibodies in $22(4 \%)$ insulin aspart-treated patients, those on insulin aspart had significantly greater binding than RHI (treatment difference $5.8 \%$ [95\% CI 4.06-7.64]) [71]. However, by 12 months, mean cross-reacting antibodies had returned to baseline in patients using insulin aspart.

In another study, insulin antibodies were detected in 48/118 (40.7\%) patients with T2D who used insulin, including 26/47 (55.3\%) using insulin aspart or biphasic insulin aspart, and surprisingly in 7/263 patients who had never used insulin [137]. A multiple regression analysis showed that insulin aspart was more antigenic than RHI. Total serum insulin levels were higher in patients (on any insulin) with insulin antibodies compared with patients without antibodies $(615.0 \pm 576$ vs $279.5 \pm 28.1 \mathrm{pmol} / \mathrm{L}$, respectively, $p<0.001)$. However, free serum insulin levels were not different with or without antibodies.

Antibody response was compared in a retrospective study of 72 children or adolescents (age 2-17 years) newly diagnosed with T1D and treated with RHI $(n=30)$ or insulin aspart $(n=42)$, and all using NPH as the basal insulin. Insulin aspart-specific and cross-reacting antibodies were measured at diagnosis and every 3-6 months for 30 months [140]. Insulin aspart-specific antibodies remained low during the period of the study, but the level of cross-reacting antibodies increased after 9 months to $48.8 \%$ for RHI and $40.2 \%$ for insulin aspart, and remained high, with no difference between treatments. However, there was no detectable influence of these elevated antibody levels on efficacy or safety.

Antibody response was also reported in a study of 27 women with gestational diabetes randomized to insulin aspart or RHI and treated from diagnosis at 18-28 weeks' gestation to 6 weeks postpartum [105]. Antibodies specific to either insulin aspart or RHI remained low $(<1 \%$ binding), but cross-reacting antibody binding increased from baseline $(0.2 \pm 3 \%$ in both treatments groups $)$ at end of study (insulin aspart $2.1 \pm 5.4 \%$, RHI $6.4 \pm 13.9 \%$ ). For the insulin aspart group, this was largely due to one patient with binding of 10.1 and $19.2 \%$ at two visits. Both treatments were described as safe in this population. Results from a subset of 97 pregnant women with T1D who participated in a larger trial $[104,141]$ also indicated that levels of insulin aspart-specific as well as RHI-specific 
antibodies were low at baseline and at gestational week 36, with no significant differences between insulin aspart and RHI [139].

\subsection{Hypoglycemia}

\subsubsection{In Patients with T1D}

Randomized trials in T1D where insulin aspart $+\mathrm{NPH}$ was compared with RHI + NPH have generally shown no difference in the incidence of overall or major hypoglycemia between treatments [70-72, 75, 77] (Table 4a). Data from a 6-month extension $(n=714)$ of the original 6-month trial with 882 subjects by Raskin et al. [71] indicated that the 24 -week results were maintained at 52 weeks. However, two of these trials have demonstrated a significantly lower rate of nocturnal hypoglycemia with insulin aspart compared with RHI [70, 71], whereas another two trials showed no difference [72, 75] (Table 4a). Additionally, although finding no difference in overall incidence of major hypoglycemic events, a trial by Heller et al. [77] indicated that the rate of major nocturnal hypoglycemia was $72 \%$ lower with insulin aspart $(0.067$ vs 0.225 events/month, $p=0.001$ ) [77]. Furthermore, in a study of 16 patients with T1D, in which acute hypoglycemia was induced by IV infusion of either insulin aspart or RHI, both insulins elicited similar symptomatic and counterregulatory responses [142].

\subsubsection{In Patients with T2D}

Results from three unpublished randomized trials of 16-24 weeks (summarized individually in a meta-analysis) indicated no difference in overall hypoglycemia for insulin aspart + NPH compared with RHI + NPH (rate ratios: 1.11 [95 \% CI 0.64-1.94], $p=0.70 ; 0.89$ [0.44-1.78], $p=0.74$; and $1.26[0.17-9.06], p=0.82$ for the three trials, respectively) [90]. Two of these trials reported results for nocturnal hypoglycemia, again indicating no difference between patients receiving insulin aspart and those receiving RHI. In one trial enrolling Chinese patients with either T1D or T2D, results were in favor of RHI for lower overall hypoglycemic episodes [143] (Table 4c). There was no difference in incidence of mild hypoglycemic events in a randomized, two-period (90 days each) crossover trial comparing mealtime insulin aspart and mealtime RHI, both with metformin $500 \mathrm{mg}$ three times daily $(2.2 \pm 1.7$ vs $2.3 \pm 1.6$ episodes/month, respectively, $p=\mathrm{NS})$ [82].

The $\mathrm{A}_{1}$ chieve observational study in patients who started or switched to basal-bolus therapy with insulin aspart has demonstrated reduced risk of hypoglycemia in people aged $\leq 40,40-65$, and $>65$ years [87] (Table 4b). Another analysis of the $A_{1}$ chieve study, examining 2026 patients using insulin aspart as the only insulin treatment, indicated that both insulin-naïve and insulin-experienced patients had reduced risk of overall hypoglycemia after adding insulin aspart to their treatment regimen [88].

\subsubsection{Meta-Analysis of T1D and T2D}

In a meta-analysis of ten trials, a fixed effect model indicated a similar rate of overall hypoglycemia for insulin aspart $+\mathrm{NPH}$ and $\mathrm{RHI}+\mathrm{NPH}$ (treatment difference $0.99 \%$ [95 \% CI 0.90-1.09], $p=0.81$ ); results were comparable using a random effects model [90]. However, the overall rate of nocturnal hypoglycemia was significantly lower for insulin aspart $+\mathrm{NPH}$ compared with $\mathrm{RHI}+\mathrm{NPH}$ (treatment difference $0.76 \%$ [95\% CI $0.67-0.85], \quad p<0.001)$; results were identical when a random effects model was used.

\subsubsection{During Step-Wise Addition of Insulin Aspart}

Safety of insulin aspart was also evaluated in two studies examining intensification of treatment via step-wise additions of insulin aspart in patients with T2D. In the STEPwise trial, insulin aspart was added to either the largest meal (SimpleSTEP) or to the meal with largest prandial glucose increments (ExtraSTEP). The number of episodes of hypoglycemia was low and similar for both regimens [91] (Table 4b). The FullSTEP trial compared a full basal-bolus regimen with a step-wise addition of insulin aspart, beginning with administration before the largest meal [92]. In that trial, there were fewer overall hypoglycemic events in the step-wise group (rate ratio 0.58 [95 \% CI 0.45-0.75], $p<0.0001$ ).

\subsubsection{In Patients with Recurrent Hypoglycemia}

The HypoAna trial examined whether basal-bolus regimens with insulin analogs could reduce the risk of hypoglycemia (compared with regimens with RHI) in those patients with T1D experiencing severe recurrent hypoglycemia at least twice a year [144]. This was a unique study because most clinical trials exclude patients with severe hypoglycemia. In this blinded endpoint, two-period (1 year each), crossover trial, 159 adult patients were randomized to either insulin aspart + insulin detemir or RHI + NPH. Due to 18 withdrawals, the intention-to-treat population was 141 patients [145]. There were 157 episodes of severe hypoglycemia with the all-analog treatment, compared with 242 episodes with the RHI regimen. Use of insulin analogs resulted in an absolute rate reduction of 0.51 episodes [95\% CI 0.19-0.84] per patient-year, 


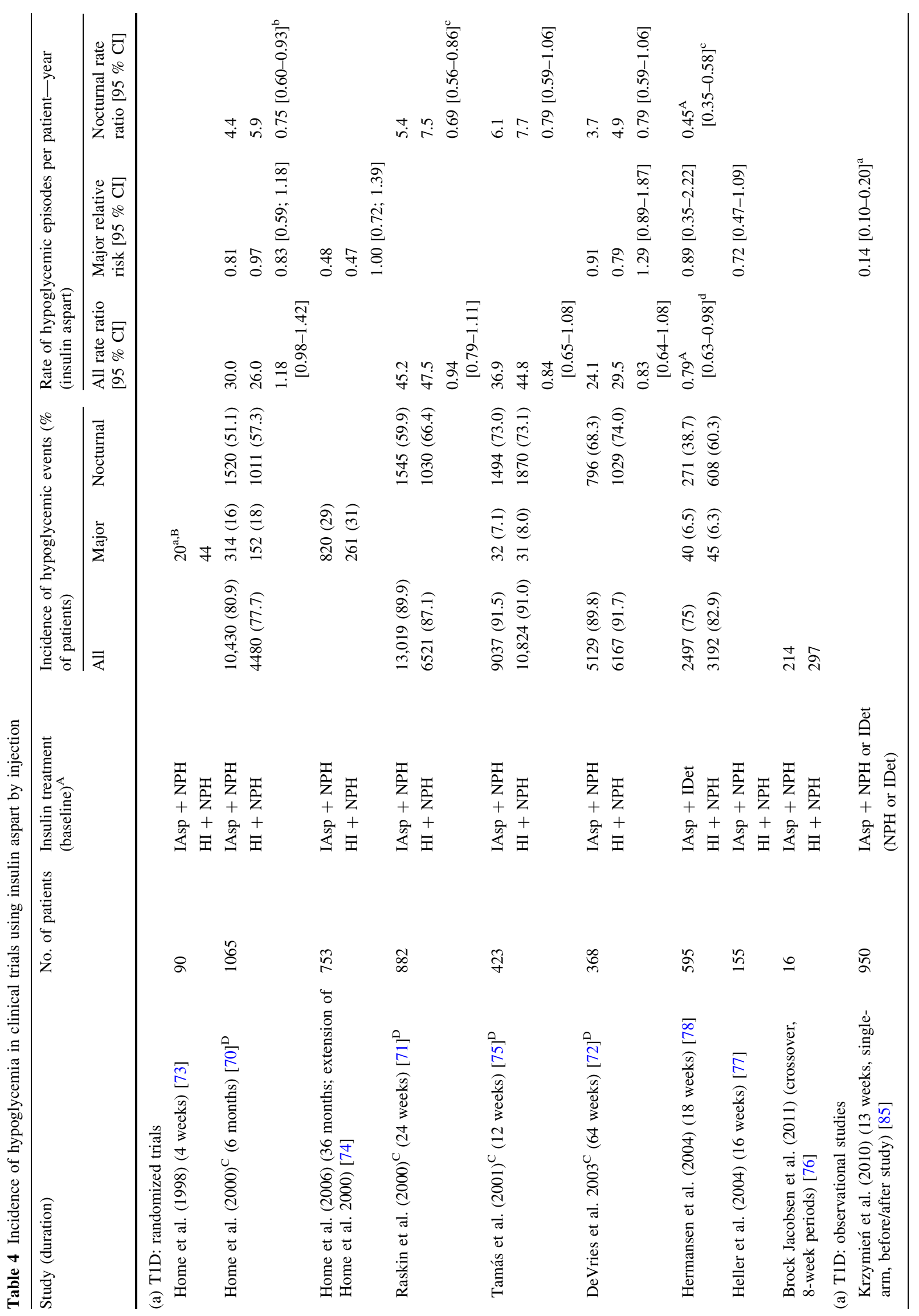




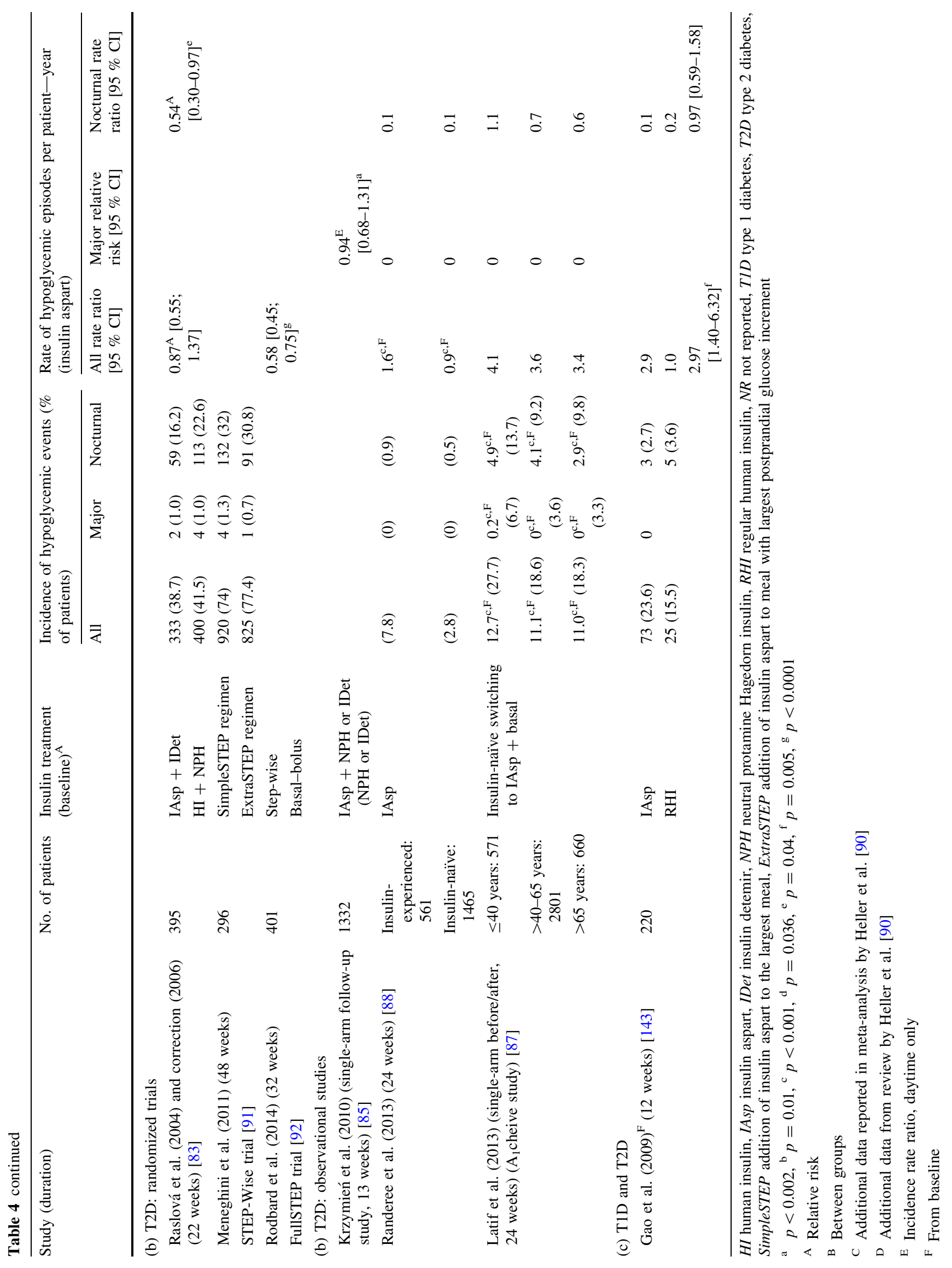


corresponding to a relative rate reduction of $29 \%$ [95\% CI 11-48], $p=0.01$, compared with the RHI regimen.

\subsubsection{In Children and Adolescents}

Insulin aspart was compared with RHI in a two-period (12 weeks each) crossover trial in 26 preschool children (age 2.4-6.9 years) using NPH as the basal insulin. The relative risk of hypoglycemia was not significantly different for insulin aspart compared with RHI [96]. Time of dosing has also been examined in a pediatric population. In a randomized, two-period (6 weeks each) crossover trial in 76 children and adolescents ( $<18$ years) treated with a basal-bolus regimen with insulin aspart plus either NPH, lente, or ultralente basal insulin, the incidence of hypoglycemia was similar whether insulin aspart was administered immediately before the start of a meal or up to $30 \mathrm{~min}$ after starting the meal [95]. When comparing insulin aspart with RHI, both with NPH, in a 26-week study of 61 children with T1D $<7$ years of age, the incidence of minor hypoglycemic episodes was similar between treatments [98].

\subsubsection{In Hospitalized Patients}

Hospitalized patients may frequently present with or develop hyperglycemia, which is itself associated with poorer outcomes [146, 147]. However, control of hyperglycemia must be accomplished without incurring hypoglycemic episodes. In a study of adults with T2D, comparing initiation of insulin aspart in the ED in conjunction with prompt initiation of insulin aspart + insulin detemir for those patients subsequently admitted to the hospital (intensive care group) compared with usual care by physicians, one intensive care patient and six usual care patients had BG $<50 \mathrm{mg} / \mathrm{dL}$ ( $p=0.11$ ) [110]. The odds of moderate hypoglycemia were higher in the intensively treated group (OR 1.93 [95\% CI 0.7-5.29]), but were lower for severe hypoglycemia (OR 0.15 [0.018-1.33]). Patients with diabetic ketoacidosis, hyperosmolar non-ketotic syndrome, or critical illness requiring ICU admission or direct surgical intervention were excluded from this study.

Incidence of hypoglycemia was studied in a randomized trial in which 130 hospitalized patients with T2D were allocated to treatment with either insulin aspart + insulin detemir or RHI + NPH [111]. There was no significant difference in the proportion of patients who experienced at least one episode of hypoglycemia (BG $<60 \mathrm{mg} / \mathrm{dL}$ ) during their hospital stay. In a study of 45 consecutive patients admitted to a hospital with diabetic ketoacidosis, SC administration of insulin aspart either every hour $(n=15)$ or every $2 \mathrm{~h}(n=15)$, indicated no difference in incidence of hypoglycemia with those receiving RHI IV $(n=15)$, with only one patient in each group experiencing a BG $\leq 60 \mathrm{mg} / \mathrm{dL}(3.3 \mathrm{mmol} / \mathrm{L})$ [107]. A study of 126 patients with refractory hyperglycemia or requiring at least $20 \mathrm{U} /$ day insulin were randomized to either meals with a standard amount of carbohydrates accompanied by fixed dosing, or flexible dosing based on carbohydrate intake [148]. Insulin aspart was administered immediately after the meal. The overall frequency of hypoglycemia was 23 and $39 \%$ in the fixed and flexible meal groups, respectively $(p=0.08)$. Although the difference was not statistically significant, the trend favored the fixed-dose group, despite the fact that insulin dose (including correctional doses) was higher for the fixed-dose group. In one observational study, 203 patients undergoing cardiac surgery were randomized to receive insulin aspart or RHI intravenously. Incidence of hypoglycemia was similar in both groups, with no patients experiencing a severe adverse event, and $24.4 \%$ of patients in the insulin aspart group and $34.1 \%$ in the RHI group experiencing moderate adverse events [149].

\subsection{Safety and Tolerability During Pregnancy}

Several papers from the same multicenter, multinational, parallel-group randomized trial in 322 women with T1D using basal-bolus therapy randomized to either insulin aspart $(n=157)$ or RHI $(n=165)$, both with NPH as basal insulin, have reported several relevant outcomes: efficacy (discussed in the Efficacy section [104]), fetal and perinatal outcomes [141], and placental transfer of antibodies (discussed under Antibodies [139]). Perinatal mortality was comparable for insulin aspart and RHI (14 and $22 / 1000$ births). However, although not statistically significant, preterm delivery tended to occur less frequently in women using insulin aspart compared with women using RHI (20.3 vs $30.6 \%$, respectively, $p=0.053$ ) [141].

Additional data demonstrating comparable safety of insulin aspart and RHI during pregnancy was obtained from a randomized, parallel-group trial of 27 women with gestational diabetes; all women were using a basal-bolus regimen with NPH as the basal insulin [105]. Women were treated and followed-up from diagnosis of gestational diabetes at 18-28 weeks to 6 weeks postpartum. Nineteen subjects reported symptomatic hypoglycemic events, with similar proportions for both insulins: $10(71 \%)$ in the insulin aspart group (53 events) and 9 (69\%) in the RHI group (23 events). No major hypoglycemic events were reported during this period. Mean infant weights, lengths, and physical exam findings were similar in each group as well, and no cases of macrosomia were reported. 


\section{Insulin Aspart in CSII}

\subsection{In Vitro/Stability Studies}

An essential requirement for use of an insulin product in CSII is adequate in vitro stability in the pump environment, as any degradation or precipitation can alter PK properties and potentially occlude catheters, leading to hyperglycemia and ketoacidosis.

Stability and potency of insulin aspart was determined to be unaffected by simulated 'worst case' storage conditions (i.e., agitation) for CSII [150]. Testing performed at 3, 4, and 7 days to detect changes in $\mathrm{pH}$, isoAspB28, desamido insulin aspart, insulin aspart-related impurities, and highmolecular weight proteins indicated no change in any of these from reference values; there was also no evidence of fibrillation or precipitation. A similar simulation study comparing insulin aspart with insulin glulisine indicated that the physical stability of insulin glulisine was reduced at both the needle end and reservoir at day 10 compared with baseline, whereas physical stability increased for insulin aspart in both the needle end and reservoir, with the exception of a sample at a flow rate of $0.9 \mathrm{U} / \mathrm{h}$ (simulating an adult user), which still maintained $90 \%$ of physical stability [151]. Another study found that all three rapidacting insulin analogs maintained physical, chemical, and biological properties after 6 days' use in the tubeless, skinadhered, Solo ${ }^{\mathrm{TM}}$ MicroPump device [152]. Tendency towards fibrillation, independent of the stabilizing excipients in their respective commercial formulations, was examined for insulin aspart, insulin lispro, and insulin glulisine in a laboratory study simulating worst-case conditions of agitation and heat [153]. Insulin aspart exhibited faster rates of fibrillation than insulin glulisine or insulin lispro when compared after stabilizing excipients were removed. However, the relevance of all of these laboratory findings for clinical use remains to be determined.

Resistance to isoelectric precipitation, which may be particularly problematic at the infusion site, has been shown to be lower with insulin aspart compared with RHI or insulin lispro in an in vitro study using decreasing $\mathrm{pH}$ ( $\sim 7.5$ to $\sim 2.6$ ) to stimulate precipitation [154]. Another in vitro study demonstrated that insulin aspart was more resistant to isoelectric precipitation than insulin glulisine [155]. In an in vitro study comparing insulin aspart, insulin lispro, and insulin glulisine, over the entire study period of nine runs of 5 days' duration, there were 48 occlusions $(n=9$ [12.5\%] for aspart; $n=13$ [18\%] for insuin lispro, and $n=26$ [36\%] for insulin glulisine). Overall, there was one early (within $72 \mathrm{~h}$ ) occlusion with insulin aspart, three with insulin glulisine, and five with insulin lispro. Insulin aspart had the lowest estimated overall probability of occlusion $(9.2 \%$ [95 \% CI $4.0-19.5$ ], $15.7 \%$ [8.1-28.1], and $40.9 \%$ [28.0-55.0], for insulin aspart, insulin lispro, and insulin glulisine, respectively) [156].

It has been postulated that changes in skin temperature below the infusion catheters might interact with choice of insulin to increase risk of occlusion [157]. In a 5-day simulation study using insulin aspart and insulin glulisine, 20 healthy volunteers wore a skin temperature probe and the catheter was inserted into an absorbent sponge in a plastic bag strapped to the abdomen to reproduce the effects of CSII [157]. The risk of occlusion was similar for both insulins (odds ratio $0.87 \%, p=0.6$ ) and considered unrelated to local skin temperature below the catheters.

\subsubsection{Insulin Aspart CSII Compared with MDI}

As shown in Table 5, insulin aspart CSII has shown comparable safety to MDI therapy [98, 112, 113, 116, 117]. These results may appear somewhat at odds with those from a meta-analysis comparing CSII with MDI, which indicated a significantly greater risk of severe hypoglycemia with MDI compared with CSII (rate ratio 4.19 [95 \% CI 2.86-6.13]) [158]. However, these results are not directly comparable as, in contrast to the meta-analysis, episodes of severe hypoglycemia were either few or absent in studies comparing insulin aspart CSII with MDI, summarized in Table 5.

\subsubsection{Insulin Aspart in CSII Versus RHI and Compared with Rapid-Acting Insulin Analogs}

Insulin aspart has also demonstrated comparable safety with RHI when both are used in CSII [99, 118-123] and with other rapid-acting insulin analogs (insulin lispro and/ or insulin glulisine) in CSII [124, 126-128] (Table 5).

In a 39-week, randomized, open-label, multicenter, crossover trial in patients with T1D using insulin glulisine, insulin aspart, and insulin aspart in CSII, the primary endpoint of incidence of catheter occlusion and unexplained hyperglycemia [95\% CI] was similar with insulin glulisine (68.4\% [62.7-74.1]), insulin aspart (62.1\% [56.2-68.1]; $p=0.04)$ and insulin lispro (61.3\% [55.4-67.3]; $p=0.03$ ) [127]. In terms of secondary outcomes, the monthly rate of unexplained hyperglycemia or perceived infusion set occlusion was significantly lower with insulin aspart $(1.32[1.02-1.61] ; p<0.001)$ and insulin lispro (1.54 [1.24-1.83]; $p<0.001)$ compared with insulin glulisine (2.02 [1.73-2.32]).

In one article summarizing the results of two randomized trials $(n=265)$ with a total treatment period of 24 weeks in patients with T1D, subjects treated with 
insulin lispro had a lower rate of documented and all-reported hypoglycemia than those treated with insulin aspart (documented hypoglycemia: 9.39 vs $10.84, p=0.003$; and 7.57 vs $8.71, p=0.012$, for trial 1 and trial 2 , respectively; all reported hypoglycemia: 15.26 vs $16.91, p=0.006$; and 16.74 vs $18.86, p<0.001$, for trial 1 and trial 2 , respectively) [130]. A significantly higher rate per 30 days of unexplained hyperglycemic episodes was noted in the insulin lispro group compared with the insulin aspart group (trial $1: 8.20$ vs $6.79, p=0.029$; trial 2 : 8.05 vs 6.54 ; $p=0.003)$.

\subsection{Effect of Insulin Aspart on Weight}

Examining the effect of insulin aspart on weight is difficult because of the competing influence of other concurrent therapies that influence weight, particularly basal insulin. For example, less weight gain has been demonstrated in basal-bolus trials with all-analog regimens (insulin aspart + insulin detemir) compared with RHI + NPH in T1D [78] and T2D [83]. However, the contribution of insulin aspart to effects on weight observed in these studies is impossible to separate from that of insulin detemir.

The effect on weight can be more directly assessed in CSII studies where insulin aspart is the sole insulin in a study arm. It is important to recognize that many of these studies are performed in children where, due to normal growth, an increase in weight is expected. Other studies are crossover trials, in which participants are exposed to all trial products. However, in one large (329 adults, 156 children) 1-year trial comparing insulin aspart CSII with insulin aspart + insulin glargine basal-bolus therapy, weight in adults increased by 2.4 and $1.8 \mathrm{~kg}$ in CSII and MDI groups, respectively $(p=0.19)$ [112]. However, in a 16-week, parallel-group trial of 146 adults randomized to either insulin aspart CSII or RHI CSII, there were no changes in weight from baseline to end of trial [121].

In a before-and-after study of 513 adults with T1D or $\mathrm{T} 2 \mathrm{D}$, there was an increase in weight 12 weeks after switching from insulin lispro CSII to insulin aspart CSII (0.58 kg [95\% CI 0.4-0.8]) [129]. However, in a smaller ( $n=21$ subjects) but much longer before-and-after study comparing RHI CSII and insulin aspart CSII in adults with T1D, BMI was nearly identical 1 year after switching to insulin aspart CSII (23.37 vs 23.70) [84].

\section{Health Economics}

Several trials have compared the cost effectiveness of insulin aspart with that of RHI [159-161] or assessed the health economic implications of intensifying treatment with insulin aspart $[162,163]$.
With respect to comparisons with RHI, an economic analysis of data from a trial comparing insulin aspart with RHI in 322 pregnant women using basal-bolus therapy with NPH as the basal insulin indicated that the cost of treatment was similar with insulin aspart and RHI (mean per-patient cost was $£ 3222$ in the insulin aspart group and $£ 3539$ in the RHI group, difference $-£ 318$ [95\% CI $-£ 1353$ to $£ 576], p=0.49)$ [159].

An economic analysis of data from patients with T2D in four European countries participating in the PREDICTIVE (Predictable Results and Experience in Diabetes Through Intensification and Control to Target: an International Variability Evaluation) study indicated that over a 35-year period, insulin aspart was projected as associated with societal and direct medical cost savings in Sweden (SEK2470 and SEK8248, respectively); with direct medical cost savings in Spain (€1382), but increased direct costs in Italy (€2235) and Poland (€743) [161]. In Germany, a decision analysis model incorporating macrovascular disease incidence in people with T2D indicated that, over a 3-year time frame, insulin aspart was (economically) superior to RHI, with the decreased incidence of macrovascular events resulting in lower costs and improved quality of life [160].

A study using records from 1793 patients with T2D from a large managed care organization in the US, who were intensifying treatment from a basal regimen + OADs to a basal-bolus regimen with insulin aspart, indicated that overall costs and diabetes-related healthcare costs decreased by US $\$ 2283$ and US $\$ 2028$, respectively $(p \leq 0.0001)$. This was attributed to a decrease in the number of in-patient visits $(0.50$ visits/patient/year; $p<0.05$, for a cost savings of US\$3019/patient) and also to reductions in $\mathrm{HbA}_{1 \mathrm{c}}(0.5 \% ; p=0.001)$ and use of OADs (56 vs $64 \% ; p<0.0001)$ [162]. Cost effectiveness of step-wise addition of bolus insulin aspart compared with full basal-bolus therapy in T2D was also evaluated in the FullSTEP trial [163]. Outcomes at end of trial such as hypoglycemic event rates, the proportion of patients achieving $\mathrm{HbA}_{1 \mathrm{c}}$ targets, and SMBG were incorporated into the models. The models indicated that in a health plan with 77,000 patients with T2D and with $7.8 \%$ intensifying each year to basal-bolus therapy, step-wise addition of insulin aspart would result in a cost savings of US $\$ 1304$ over a full basal-bolus regimen for each patient requiring intensification.

\section{Future Needs and Opportunities}

Fifteen years of clinical use of insulin aspart have demonstrated that it maintains PK and PD properties in a variety of patient populations. However, despite these 


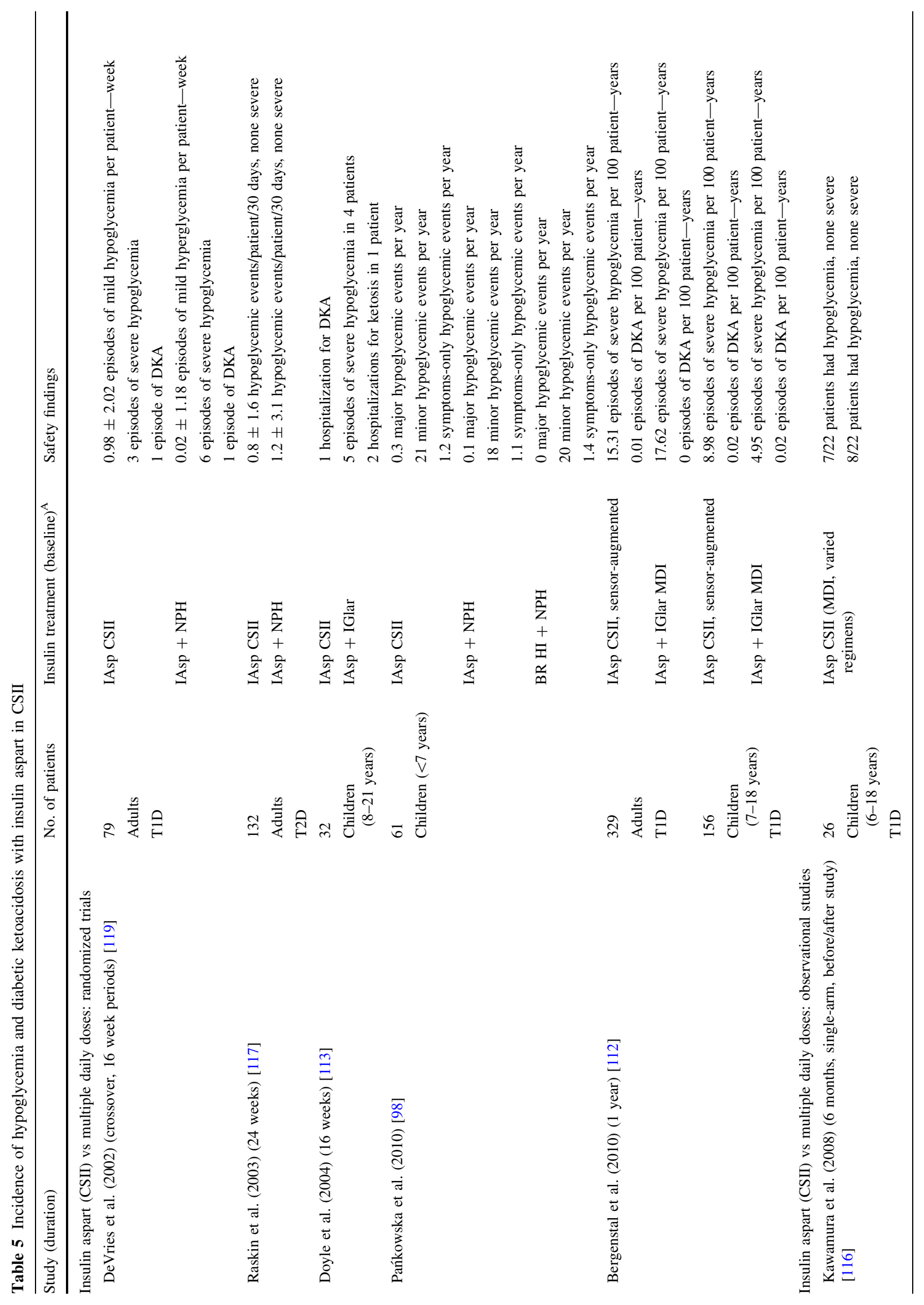




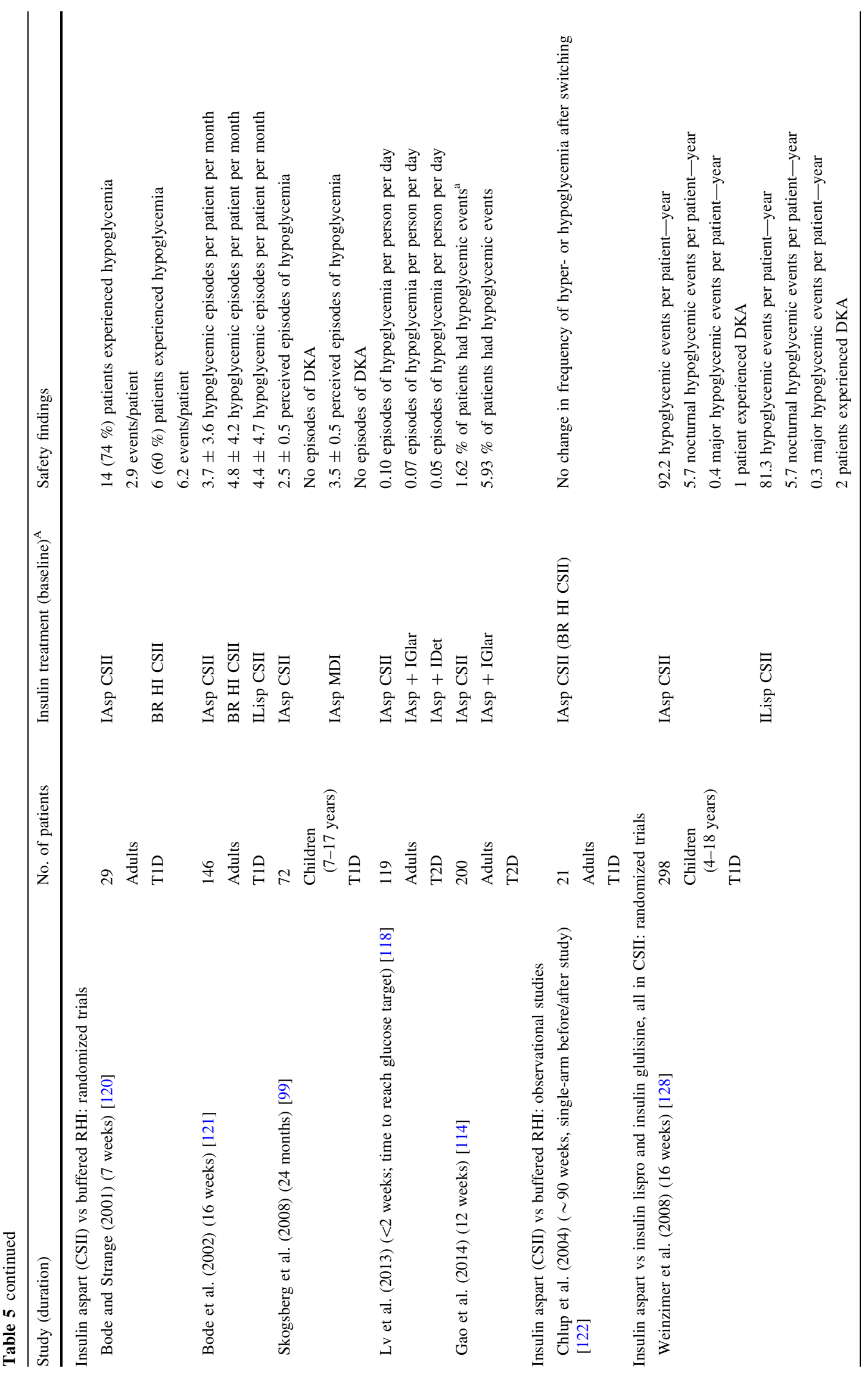




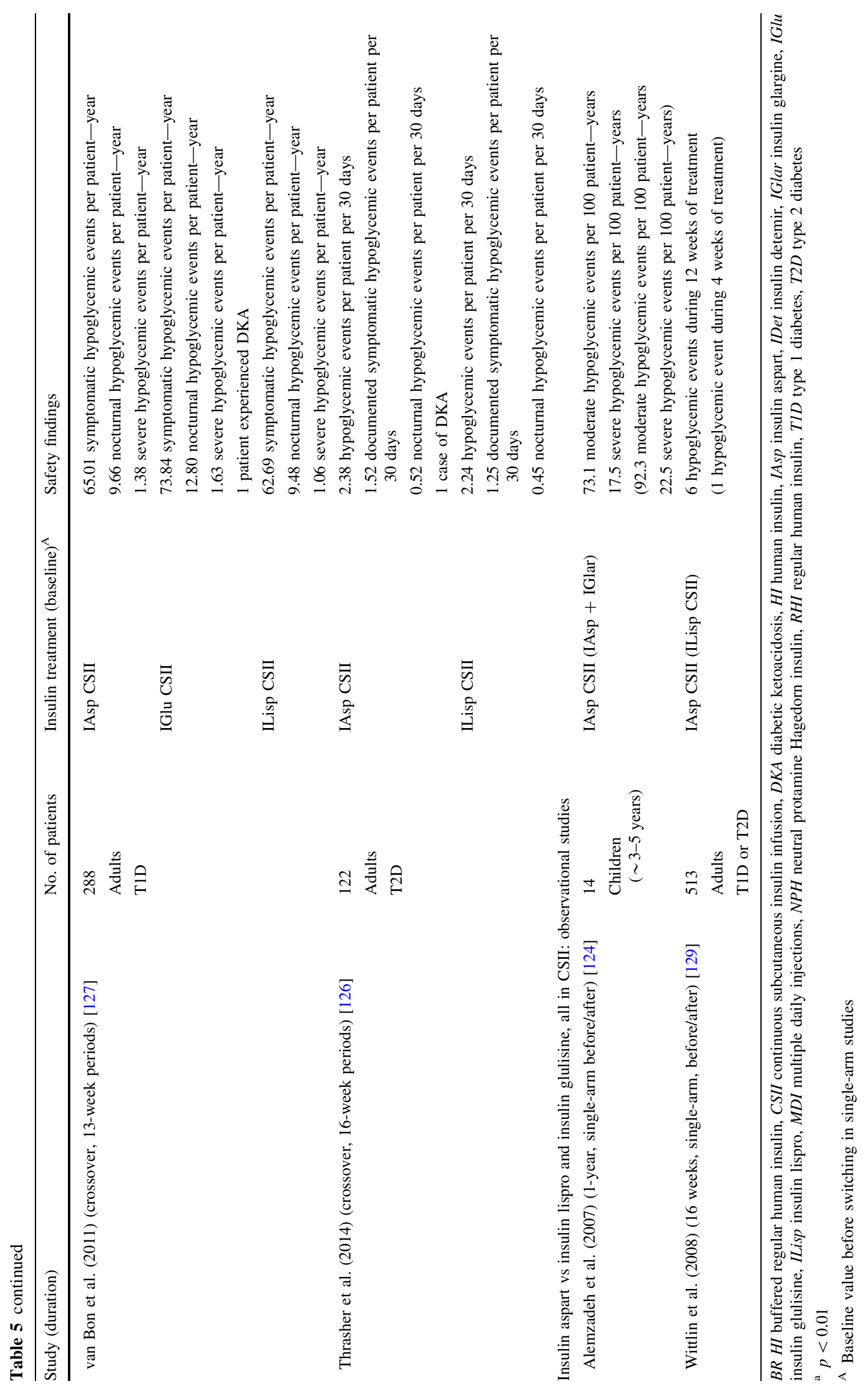


improvements, rapid-acting insulin aspart still does not fully mimic the PK and PD endogenous insulin profile. The next generation of insulin aspart ('faster-acting insulin aspart') is currently in clinical development and preliminary results have been reported [164, 165]. Faster-acting insulin aspart contains excipients nicotinamide and arginine. The excipients result in a stable formulation and faster initial absorption after SC injection [164].

In a glucose clamp crossover study, 52 adult patients with T1D were randomized to either insulin aspart or faster-acting insulin aspart [164]. Faster-acting insulin aspart took less than half of the time to onset of appearance (4.9 vs $11.2 \mathrm{~min}$ ) and showed higher early exposure. During the first $30 \mathrm{~min}$, area under the serum insulin aspart curve with faster-acting insulin aspart was twofold higher than insulin aspart (treatment ratio 2.05 [95\% CI 1.76-2.38]). Fasteracting insulin aspart had $50 \%$ greater glucose-lowering effect within the first 30 min $\left(\mathrm{AUC}_{\mathrm{GIR}, 0-30 \mathrm{~min}}\right.$ treatment ratio 1.48 [95\% CI 1.13-2.02]).

In a double-blind, randomized crossover study, two formulations of faster-acting insulin aspart (only data for the faster aspart formulation undergoing further development were presented) were compared with insulin aspart in CSII in 43 adults for 14 days [165]. Faster-acting insulin aspart had a significantly greater glucose-lowering effect after a standardized meal than insulin aspart, as shown by a lower mean change in plasma glucose from 0 to $2 \mathrm{~h}(3.03$ and $4.02 \mathrm{mmol} / \mathrm{L}$, respectively; treatment difference $-0.99 \mathrm{mmol} / \mathrm{L}$ [ $95 \% \mathrm{CI}-1.95$ to -0.03 ], $p<0.05$ ). The mean increment in interstitial glucose (measured with blinded continuous glucose monitoring) was also significantly lower with faster-acting insulin aspart at $60 \mathrm{~min}$ (treatment difference $-0.66 \mathrm{mmol} / \mathrm{L}[95 \% \mathrm{CI}-0.95$ to $-0.37] ; p<0.001$ ) and $120 \mathrm{~min}$ (treatment difference -0.58 [95\% CI -0.97 to -0.19$], p<0.01$ ) after all meals. The duration of low interstitial glucose (i.e., $\leq 3.9 \mathrm{mmol} / \mathrm{L}$ per $24 \mathrm{~h}$ ) was also significantly longer for insulin aspart compared with faster-acting insulin aspart ( 2.45 and $2.03 \mathrm{~h}$, respectively, mean difference -0.42 [95\% CI -0.72 to -0.11$]$ ).

\section{Conclusion}

Insulin aspart is structurally identical to both RHI and endogenous insulin, except for replacement of a single proline amino acid at position 28 in the C-terminal area of the insulin $\beta$-chain with an aspartic acid residue. This substitution weakens the natural tendency towards selfassociation between insulin monomers, thereby accelerating absorption after SC injection. Following SC injection, insulin aspart had a faster absorption, shorter time to peak activity, and a more rapid and shorter duration of action than RHI.

The PK profiles for insulin aspart and insulin lispro are similar, whereas the absorption of insulin glulisine appears slightly more rapid. Head-to-head trials comparing insulin aspart with insulin lispro have generally shown comparable $\mathrm{PD}$, whereas insulin glulisine had a slightly earlier onset. There seem to be no clinically important relationships between insulin aspart PK and BMI, renal impairment, or hepatic impairment.

In adult patients with $\mathrm{T} 1 \mathrm{D}$, insulin aspart demonstrated improved postprandial glucose control compared with RHI after meals. A meta-analysis of trials of basal-bolus therapy in T1D and T2D has shown significantly better postprandial glucose control with insulin aspart treatment compared with RHI. Insulin aspart significantly reduces $\mathrm{HbA}_{1 \mathrm{c}}$ compared with RHI in T1D, and in T2D both insulins appear to influence $\mathrm{HBA}_{1 \mathrm{c}}$ similarly. A metaanalysis in T1D and $\mathrm{T} 2 \mathrm{D}$ has shown better $\mathrm{HbA}_{1 \mathrm{c}}$ reduction with insulin aspart compared with RHI. Furthermore, comparisons of insulin aspart with other analogs in CSII have generally shown no significant differences in $\mathrm{HbA}_{1 \mathrm{c}}$ between treatment groups, and studies have suggested that insulin aspart has a lower risk of occlusion than either insulin lispro or insulin glulisine. Randomized trials in T1D have generally shown no difference in the incidence of overall or major hypoglycemia between treatments. Insulin aspart administered as CSII and MDI therapy have shown comparable safety.

Despite these improvements, insulin aspart still does not fully mimic the PK and PD properties of the endogenous insulin profile. An ultrarapid-acting insulin-'faster-acting insulin aspart' - appears to have twice-as-fast onset of appearance, 2-fold higher insulin exposure, and $50 \%$ greater insulin action within the first $30 \mathrm{~min}$ than insulin aspart. More closely approaching the physiological insulin secretion profile could lead to earlier inhibition of hepatic glucose production and improved postprandial glucose control. The efficacy and safety of faster-acting insulin aspart need to be demonstrated in large clinical trials.

\section{Compliance with Ethical Standards}

Funding The authors are grateful to Gary Patronek and Grant Womack of Watermeadow Medical, for writing and editing assistance in the development of this manuscript. This assistance was funded by Novo Nordisk, which also had a role in the review of the manuscript for scientific accuracy.

Conflict of interest Kjeld Hermansen has served on advisory boards and speaker bureaus of Novo Nordisk, Astra Zeneca, Sanofi, Eli Lilly, Boehringer Ingleheim, and Merck. The authors have no other relevant affiliation or financial involvement with any organization or entity with a financial interest or financial conflict with the subject matter or material discussed in this manuscript. 
Open Access This article is distributed under the terms of the Creative Commons Attribution-NonCommercial 4.0 International License (http://creativecommons.org/licenses/by-nc/4.0/), which permits any noncommercial use, distribution, and reproduction in any medium, provided you give appropriate credit to the original author(s) and the source, provide a link to the Creative Commons license, and indicate if changes were made.

\section{References}

1. International Diabetes Federation. IDF Diabetes Atlas Update 2013. 6th ed. Available at: http://www.idf.org/diabetesatlas/ update-2014. Accessed 11 February 2015.

2. Diabetes Control and Complications Trial Research Group. The effect of intensive treatment of diabetes on the development and progression of long-term complications in insulin-dependent diabetes mellitus. N Engl J Med. 1993;329:977-86.

3. Diabetes Control and Complications Trial Research Group. The absence of a glycaemic threshold for development of long-term complications: the perspective of the DCCT. Diabetes. 1996;45:1289-98.

4. DCCT, Writing Team for the Diabetes Control and Complications Trial/Epidemiology of Diabetes Interventions and Complications Research Group. Effect of intensive therapy on the microvascular complications of type 1 diabetes mellitus. JAMA. 2002;287:2563-9.

5. Nathan DM, Bayless M, Cleary P, Genuth S, Gubitosi-Klug R, Lachin JM, DCCT/EDIC Research Group, et al. Diabetes control and complications trial/epidemiology of diabetes interventions and complications study at 30 years: advances and contributions. Diabetes. 2013;62:3976-86.

6. Orchard TJ, Nathan DM, Zinman B, Cleary P, Brillon D, Backlund JY, Writing Group for the DCCT/EDIC Research Group, et al. Association between 7 years of intensive treatment of type 1 diabetes and long-term mortality. JAMA. 2015;313:45-53.

7. UK Prospective Diabetes Study (UKPDS) Group. Intensive blood-glucose control with sulphonylureas or insulin compared with conventional treatment and risk of complications in patients with type 2 diabetes (UKPDS 33. Lancet. 1998;352:837-53.

8. Stratton IM, Adler AI, Neil HA, Matthews DR, Manley SE, Cull $\mathrm{CA}$, et al. Association of glycaemia with macrovascular and microvascular complications of type 2 diabetes (UKPDS 35): prospective observational study. BMJ. 2000;321:405-12.

9. Holman RR, Paul SK, Bethel MA, Matthews DR, Neil HA. 10 -year follow-up of intensive glucose control in type 2 diabetes. N Engl J Med. 2008;359:1577-89.

10. Boussageon R, Bejan-Angoulvant T, Saadatian-Elahi M, Lafont $\mathrm{S}$, Bergeonneau C, Kassaï B, et al. Effect of intensive glucose lowering treatment on all cause mortality, cardiovascular death, and microvascular events in type 2 diabetes: meta-analysis of randomised controlled trials. BMJ. 2011;343:d4169.

11. Currie CJ, Peters JR, Tynan A, Evans M, Heine RJ, Bracco OL, et al. Survival as a function of $\mathrm{HbA}(1 \mathrm{c})$ in people with type 2 diabetes: a retrospective cohort study. Lancet. 2010;375:481-9.

12. Dailey G. Overall mortality in diabetes mellitus: where do we stand today? Diabetes Technol Ther. 2011;13(Suppl 1):S65-74.

13. Dailey G. Early and intensive therapy for management of hyperglycemia and cardiovascular risk factors in patients with type 2 diabetes. Clin Ther. 2011;33:665-78.

14. MacIsaac RJ, Jerums G. Intensive glucose control and cardiovascular outcomes in type 2 diabetes. Heart Lung Circ. 2011;20:647-54.
15. Terry T, Raravikar K, Chokrungvaranon N, Reaven PD. Does aggressive glycemic control benefit macrovascular and microvascular disease in type 2 diabetes? Insights from ACCORD, ADVANCE, and VADT. Curr Cardiol Rep. 2012;14:79-88.

16. Inzucchi SE, Bergenstal RM, Buse JB, Diamant M, Ferrannini E, Nauck M, et al. Management of hyperglycemia in type 2 diabetes, 2015: a patient-centered approach: update to a position statement of the American Diabetes Association and the European Association for the Study of Diabetes. Diabetes Care. 2015;38:140-9.

17. Pozzilli P, Strollo R, Bonora E. One size does not fit all glycemic targets for type 2 diabetes. J Diabetes Investig. 2014;5:134-41.

18. Monnier L, Lapinski H, Colette C. Contributions of fasting and postprandial plasma glucose increments to the overall diurnal hyperglycemia of type 2 diabetic patients: variations with increasing levels of $\mathrm{HbA}(1 \mathrm{c})$. Diabetes Care. 2003;26:881-5.

19. Bonora E, Muggeo M. Postprandial blood glucose as a risk factor for cardiovascular disease in Type II diabetes: the epidemiological evidence. Diabetologia. 2001;44:2107-14.

20. Ceriello A, Taboga C, Tonutti L, Quagliaro L, Piconi L, Bais B, et al. Evidence for an independent and cumulative effect of postprandial hypertriglyceridemia and hyperglycemia on endothelial dysfunction and oxidative stress generation: effects of short- and long-term simvastatin treatment. Circulation. 2002;106:1211-8.

21. Ceriello A, Hanefeld M, Leiter L, Monnier L, Moses A, Owens D, et al. Postprandial glucose regulation and diabetic complications. Arch Intern Med. 2004;164:2090-5.

22. DECODE Study Group, The European Diabetes Epidemiology Group. Glucose tolerance and cardiovascular mortality: comparison of fasting and 2-hour diagnostic criteria. Arch Intern Med. 2001;161:397-405.

23. Hanefeld M, Koehler C, Schaper F, Fuecker K, Henkel E, Temelkova-Kurktschiev T. Postprandial plasma glucose is an independent risk factor for increased carotid intima-media thickness in non-diabetic individuals. Atherosclerosis. 1999;144:229-35.

24. Hanefeld M, Temelkova-Kurktschiev T. Control of post-prandial hyperglycemia - an essential part of good diabetes treatment and prevention of cardiovascular complications. Nutr Metab Cardiovasc Dis. 2002;12:98-107.

25. Standl E, Schnell O, Ceriello A. Postprandial hyperglycemia and glycemic variability: should we care? Diabetes Care. 2011;34(Suppl 2):S120-7.

26. Brange J, Owens DR, Kang S, Vølund A. Monomeric insulins and their experimental and clinical implications. Diabetes Care. 1990;13:923-54.

27. Brange J. Design of insulin analogues for meal-related therapy. J Diabetes Complicat. 1993; 7:106-12.

28. Rasmussen CH, Røge RM, Ma Z, Thomsen M, Thorisdottir RL, Chen JW, et al. Insulin aspart pharmacokinetics: an assessment of its variability and underlying mechanisms. Eur J Pharm Sci. 2014;62:65-75

29. Lindholm A. New insulins in the treatment of diabetes mellitus. Best Pract Res Clin Gastroenterol. 2002;16:475-92.

30. Nosek L, Roggen K, Heinemann L, Gottschalk C, Kaiser M, Arnolds S, et al. Insulin aspart has a shorter duration of action than human insulin over a wide dose-range. Diabetes Obes Metab. 2013;15:77-83.

31. Overmann H, Heinemann L. Injection-meal interval: recommendations of diabetologists and how patients handle it. Diabetes Res Clin Pract. 1999;43:137-42.

32. Chapman TM, Noble S, Goa KL. Insulin aspart: a review of its use in the management of type 1 and 2 diabetes mellitus. Drugs. 2002;62:1945-81 (erratum in: Drugs. 2003;63:512). 
33. Whittingham JL, Edwards DJ, Antson AA, Clarkson JM, Dodson GG. Interactions of phenol and $\mathrm{m}$-cresol in the insulin hexamer, and their effect on the association properties of B28 pro $\rightarrow$ Asp insulin analogues. Biochemistry. 1998;37:11516-23.

34. Drejer K. The bioactivity of insulin analogues from in vitro receptor binding to in vivo glucose uptake. Diabetes Metab Rev. 1992;8:259-85.

35. Lindholm A, Jacobsen LV. Clinical pharmacokinetics and pharmacodynamics of insulin aspart. Clin Pharmacokinet. 2001;40:641-59.

36. Heinemann L, Heise T, Jorgensen LN, Starke AA. Action profile of the rapid acting insulin analogue: human insulin B28Asp. Diabet Med. 1993;10:535-9.

37. Heinemann L, Kapitza C, Starke A, Heise T. Time-action profile of the insulin analogue B28Asp. Diabet Med. 1996;13:683-4.

38. Mudaliar SR, Lindberg FA, Joyce M, Beerdsen P, Strange P, Lin A, et al. Insulin aspart (B28 asp-insulin): a fast-acting analog of human insulin: absorption kinetics and action profile compared with regular human insulin in healthy nondiabetic subjects. Diabetes Care. 1999;22:1501-6.

39. Home PD, Barriocanal L, Lindholm A. Comparative pharmacokinetics and pharmacodynamics of the novel rapid-acting insulin analogue, insulin aspart, in healthy volunteers. Eur J Clin Pharmacol. 1999;55:199-203.

40. Kaku K, Matsuda M, Urae A, Irie S. Pharmacokinetics and pharmacodynamics of insulin aspart, a rapid-acting analog of human insulin, in healthy Japanese volunteers. Diabetes Res Clin Pract. 2000;49:119-26.

41. Lindholm A, McEwen J, Riis AP. Improved postprandial glycaemic control with insulin aspart-a randomized double-blind cross-over trial in type 1 diabetes mellitus. Diabetes Care. 1999;22:801-5.

42. Ma Z, Parkner T, Frystyk J, Laursen T, Lauritzen T, Christiansen JS. A comparison of pharmacokinetics and pharmacodynamics of insulin aspart, biphasic insulin aspart 70, biphasic insulin aspart 50, and human insulin: a randomized, quadruple crossover study. Diabetes Technol Ther. 2012;14:589-95.

43. Ando H, Kurita S, Shimizu A, Kato K, Ishikura K, Taji K, et al. Pharmacokinetics and pharmacodynamics of insulin aspart in patients with type 2 diabetes: assessment using a meal tolerance test under clinical conditions. Clin Exp Pharmacol Physiol. 2012;39:528-34.

44. Perriello G, Pampanelli S, Porcellati F, Avogaro A, Bosi E, Petrella G, et al. Insulin aspart improves meal time glycaemic control in patients with type 2 diabetes: a randomized, stratified, double-blind and cross-over trial. Diabet Med. 2005;22:606-11.

45. Johansson UB, Amsberg S, Hannerz L, Wredling R, Adamson $\mathrm{U}$, Arnqvist HJ, et al. Impaired absorption of insulin aspart from lipohypertrophic injection sites. Diabetes Care. 2005;28:2025-7.

46. Engwerda EE, Abbink EJ, Tack CJ, de Galan BE. Improved pharmacokinetic and pharmacodynamic profile of rapid-acting insulin using needle-free jet injection technology. Diabetes Care. 2011;34:1804-8.

47. Engwerda EE, Tack CJ, de Galan BE. Needle-free jet injection of rapid-acting insulin improves early postprandial glucose control in patients with diabetes. Diabetes Care. 2013;36:3436-41.

48. von Mach MA, Brinkmann C, Hansen T, Weilemann LS, Beyer J. Differences in pharmacokinetics and pharmacodynamics of insulin lispro and aspart in healthy volunteers. Exp Clin Endocrinol Diabetes. 2002;110:416-9.

49. Hedman CA, Lindström T, Arnqvist HJ. Direct comparison of insulin lispro and aspart shows small differences in plasma insulin profiles after subcutaneous injection in type 1 diabetes. Diabetes Care. 2001;24:1120-1.
50. Homko C, Deluzio A, Jimenez C, Kolaczynski JW, Boden G. Comparison of insulin aspart and lispro: pharmacokinetic and metabolic effects. Diabetes Care. 2003;26:2027-31.

51. Plank J, Wutte A, Brunner G, Siebenhofer A, Semlitsch B, Sommer R, et al. A direct comparison of insulin aspart and insulin lispro in patients with type 1 diabetes. Diabetes Care. 2002;25:2053-7.

52. Arnolds S, Rave K, Hövelmann U, Fischer A, Sert-Langeron C, Heise T. Insulin glulisine has a faster onset of action compared with insulin aspart in healthy volunteers. Exp Clin Endocrinol Diabetes. 2010;118:662-4.

53. Bolli GB, Luzio S, Marzotti S, Porcellati F, Sert-Langeron C, Charbonnel B, et al. Comparative pharmacodynamic and pharmacokinetic characteristics of subcutaneous insulin glulisine and insulin aspart prior to a standard meal in obese subjects with type 2 diabetes. Diabetes Obes Metab. 2011;13:251-7.

54. Heinemann L, Weyer C, Rauhaus M, Heinrichs S, Heise T. Variability of the metabolic effect of soluble insulin and the rapid-acting insulin analog insulin aspart. Diabetes Care. 1998;21:1910-4.

55. Rosenfalck A, Thorsby P, Kjems L, Birkeland K, Dejgaard A, Hanssen $\mathrm{KF}$, et al. Improved postprandial glycaemic control with insulin Aspart in type 2 diabetic patients treated with insulin. Acta Diabetologia. 2000;37:41-6.

56. Ohta A, Arai K, Nishine A, Sada Y, Kato H, Fukuda H, et al. Comparison of daily glucose excursion by continuous glucose monitoring between type 2 diabetic patients receiving preprandial insulin aspart or postprandial insulin glulisine. Endocr $\mathbf{J}$. 2013;60:173-7.

57. Gredal C, Rosenfalck AM, Dejgaard A, Hilsted J. Targeting postprandial hyperglycaemia in patients with recently diagnosed type 2 diabetes with a fixed, weight-based dose of insulin Aspart. Scand J Clin Lab Invest. 2008;68:739-44.

58. Tanaka N, Hiura Y. Effects of rapid-acting insulin analogues insulin glulisine and insulin aspart on postprandial glycemic excursion with single bout of exercise in patients with type 2 diabetes. Endocr J. 2015;62:411-6.

59. Krones R, Schütte C, Heise T. The rapid-acting properties of insulin aspart are preserved in elderly people with type 2 diabetes. Diabetes Obes Metab. 2009;11:41-4.

60. Meneilly GS. A comparison of insulin aspart and regular insulin in elderly patients with type 2 diabetes. Diabetes Obes Metab. 2007;9:754-5.

61. Ruan Y, Elleri D, Allen JM, Tauschmann M, Wilinska ME, Dunger DB, et al. Pharmacokinetics of diluted (U20) insulin aspart compared with standard (U100) in children aged 3-6 years with type 1 diabetes during closed-loop insulin delivery: a randomised clinical trial. Diabetologia. 2015;58:687-90.

62. Mortensen H, Lindholm A, Olsen B, Hylleberg B. Rapid appearance and onset of action of insulin aspart in paediatric subjects with type 1 diabetes. Eur J Paediatr. 2000;159:483-8.

63. Petersen SB, Kildegaard J, Nielsen FS, Søndergaard E, Parkner $\mathrm{T}$, Laursen $\mathrm{T}$, et al. Pharmacokinetics following continuous subcutaneous insulin infusion of insulin aspart with or without initial subcutaneous bolus. Diabetes Obes Metab. 2010;12:334-40.

64. Haidar A, Elleri D, Kumareswaran K, Leelarathna L, Allen JM, Caldwell K, et al. Pharmacokinetics of insulin aspart in pumptreated subjects with type 1 diabetes: reproducibility and effect of age, weight, and duration of diabetes. Diabetes Care. 2013;36:e173-4.

65. Ihlo CA, Lauritzen T, Sturis J, Skyggebjerg O, Christiansen JS, Laursen T. Pharmacokinetics and pharmacodynamics of different modes of insulin pump delivery. A randomized, controlled study comparing subcutaneous and intravenous administration of insulin aspart. Diabet Med. 2011;28:230-6. 
66. Swan KL, Dziura JD, Steil GM, Voskanyan GR, Sikes KA, Steffen AT, et al. Effect of age of infusion site and type of rapidacting analog on pharmacodynamic parameters of insulin boluses in youth with type 1 diabetes receiving insulin pump therapy. Diabetes Care. 2009;32:240-4.

67. Holmes G, Galitz L, Hu P, Lyness W. Pharmacokinetics of insulin aspart in obesity, renal impairment, or hepatic impairment. Br J Clin Pharmacol. 2005;60:469-76.

68. Kulozik F, Hasslacher C. Insulin requirements in patients with diabetes and declining kidney function: differences between insulin analogues and human insulin? Ther Adv Endocrinol Metab. 2013;4:113-21.

69. Pettitt DJ, Ospina P, Kolaczynski JW, Jovanovic L. Comparison of an insulin analog, insulin aspart, and regular human insulin with no insulin in gestational diabetes mellitus. Diabetes Care. 2003;26:183-6.

70. Home P, Lindholm A, Riis A, European Insulin Aspart Study Group. Insulin aspart vs. human insulin in the management of long-term blood glucose control in Type 1 diabetes mellitus: a randomized controlled trial. Diabet Med. 2000;17:762-70.

71. Raskin P, Guthrie RA, Leiter L, Riis A, Jovanovic L. Use of insulin aspart, a fast-acting insulin analog, as the mealtime insulin in the management of patients with type 1 diabetes. Diabetes Care. 2000;23:583-8.

72. DeVries JH, Lindholm A, Jacobsen JL, Heine RJ, Home PD, TriContinental Insulin Aspart Study Group. A randomized trial of insulin aspart with intensified basal NPH insulin supplementation in people with Type 1 diabetes. Diabet Med. 2003;20:312-8.

73. Home PD, Lindholm A, Hylleberg B, Round P. Improved glycemic control with insulin aspart. A multicenter randomized double-blind crossover trial in type 1 diabetic patients. Diabetes Care. 1998;21:1904-9.

74. Home PD, Hallgren P, Usadel KH, Sane T, Faber J, Grill V, et al. Pre-meal insulin aspart compared with pre-meal soluble human insulin in type 1 diabetes. Diabetes Res Clin Pract. 2006; 71:131-9.

75. Tamás G, Marre M, Astorga R, Dedov I, Jacobsen J, Lindholm A, Insulin Aspart Study Goup. Glycaemic control in type 1 diabetic patients using optimised insulin aspart or human insulin in a randomised multinational study. Diabetes Res Clin Pract. 2001;54:105-14.

76. Brock Jacobsen I, Vind BF, Korsholm L, Flyvbjerg A, Frystyk J, Holst JJ, et al. Counter-regulatory hormone responses to spontaneous hypoglycaemia during treatment with insulin Aspart or human soluble insulin: a double-blinded randomized cross-over study. Acta Physiol (Oxf). 2011;202:337-47.

77. Heller SR, Colagiuri S, Vaaler S, Wolffenbuttel BH, Koelendorf $\mathrm{K}$, Friberg $\mathrm{HH}$, et al. Hypoglycaemia with insulin aspart: a double-blind, randomised, crossover trial in subjects with Type 1 diabetes. Diabet Med. 2004;21:769-75.

78. Hermansen K, Fontaine P, Kukolja KK, Peterkova V, Leth G, Gall MA. Insulin analogues (insulin detemir and insulin aspart) vs. traditional human insulins (NPH insulin and regular human insulin) in basal-bolus therapy for patients with type 1 diabetes. Diabetologia. 2004;47:622-9.

79. Bretzel RG, Arnolds S, Medding J, Linn T. A direct efficacy and safety comparison of insulin aspart, human soluble insulin, and human premix insulin (70/30) in patients with type 2 diabetes. Diabetes Care. 2004;27:1023-7.

80. Gallagher A, Home PD. The effect of improved post-prandial blood glucose control on post-prandial metabolism and markers of vascular risk in people with Type 2 diabetes. Diabetes Res Clin Pract. 2005;67:196-203.

81. Herrmann BL, Kasser C, Keuthage W, Huptas M, Dette H, Klute A. Comparison of insulin aspart vs. regular human insulin with or without insulin detemir concerning adipozytokines and metabolic effects in patients with type 2 diabetes mellitus. Exp Clin Endocrinol Diabetes. 2013;121:210-3.

82. Pala L, Mannucci E, Dicembrini I, Rotella CM. A comparison of mealtime aspart and human insulin in combination with metformin in type 2 diabetes patients. Diabetes Res Clin Pract. 2007;78:132-5.

83. Raslová K, Bogoev M, Raz I, Leth G, Gall MA, Hâncu N. Insulin detemir and insulin aspart: a promising basal-bolus regimen for type 2 diabetes. Diabetes Res Clin Pract. 2004;66:193-201 (erratum in: Diabetes Res Clin Pract. 2006;72:112).

84. Chlup R, Zapletalová J, Seckar P, Malá E, Doubravová B, Táncosová $\mathrm{S}$, et al. Benefits of complementary therapy with insulin aspart versus human regular insulin in persons with type 2 diabetes mellitus. Diabetes Technol Ther. 2007;9:223-31.

85. Krzymień J, Kobli T, Nazar M. Multicenter, open-label, nonrandomized, observational safety study in subjects using insulin aspart in basal-bolus regimen for the treatment of diabetes. Pol Arch Med Wewn. 2010;120:444-50.

86. Gallagher A, Butler TJ, Home PD. The effect of the optimal use of rapid-acting insulin analogues on insulin secretion in Type 2 diabetes. Diabetes Res Clin Pract. 2007;76:327-34.

87. Latif ZA, Hussein Z, Litwak L, El Naggar N, Chen JW, Soewondo P. Safety and effectiveness of insulin aspart in basalbolus regimens regardless of age: a1chieve study results. Diabetes Ther. 2013;4:103-18.

88. Randeree H, Liebl A, Hajjaji I, Khamseh M, Zajdenverg L, Chen JW, et al. Safety and effectiveness of bolus insulin aspart in people with type 2 diabetes: A1chieve sub-analysis. Diabetes Ther. 2013;4:153-66.

89. Cucinotta D, Caputo S, Mannucci E, Nicolucci A, Pellegrini F, Perriello G, et al. Safety and efficacy of insulin aspart and soluble human insulin in Type 2 diabetes mellitus. Minerva Endocrinol. 2012;37:357-66.

90. Heller S, Bode B, Kozlovski P, Svendsen AL. Meta-analysis of insulin aspart versus regular human insulin used in a basal-bolus regimen for the treatment of diabetes mellitus. J Diabetes. 2013;5:482-91.

91. Meneghini L, Mersebach H, Kumar S, Svendsen AL, Hermansen K. Comparison of 2 intensification regimens with rapid-acting insulin aspart in type 2 diabetes mellitus inadequately controlled by once-daily insulin detemir and oral diabetes drugs: the step-wise randomized study. Endocr Pract. 2011;5:727-36.

92. Rodbard HW, Visco VE, Andersen H, Hiort LC, Shu DH. Treatment intensification with stepwise addition of prandial insulin aspart boluses compared with full basal-bolus therapy (FullSTEP Study): a randomised, treat-to-target clinical trial. Lancet Diabetes Endocrinol. 2014;2:30-7.

93. Rathmann W, Kostev K. Lower incidence of recorded cardiovascular outcomes in patients with type 2 diabetes using insulin aspart vs. those on human regular insulin: observational evidence from general practices. Diabetes Obes Metab. 2013;15:358-63.

94. Naruse R, Takebayashi K, Morita K, Aso Y, Inukai T. Comparison of effects of insulin aspart three times a day versus insulin detemir once a day on oxidative stress in patients with type 2 diabetes. Endocr J. 2011;58:1055-63.

95. Danne T, Aman J, Schober E, Deiss D, Jacobsen JL, Friberg $\mathrm{HH}$, et al. A comparison of postprandial and preprandial administration of insulin aspart in children and adolescents with type 1 diabetes. Diabetes Care. 2003;26:2359-64.

96. Danne T, Råstam J, Odendahl R, Näke A, Schimmel U, Szczepanski R, et al. Parental preference of prandial insulin aspart compared with preprandial human insulin in a basalbolus scheme with NPH insulin in a 12-wk crossover study of 
preschool children with type 1 diabetes. Pediatr Diabetes. 2007;5:278-85.

97. Cemeroglu AP, Kleis L, Wood A, Parkes C, Wood MA, Davis AT. Comparison of the effect of insulin glulisine to insulin aspart on breakfast postprandial blood glucose levels in children with type 1 diabetes mellitus on multiple daily injections. Endocr Pract. 2013;19:614-9.

98. Pańkowska E, Nazim J, Szalecki M, Urban M. Equal metabolic control but superior caregiver treatment satisfaction with insulin aspart in preschool children. Diabetes Technol Ther. 2010;12:413-8.

99. Skogsberg L, Fors H, Hanas R, Chaplin JE, Lindman E, Skogsberg J. Improved treatment satisfaction but no difference in metabolic control when using continuous subcutaneous insulin infusion vs. multiple daily injections in children at onset of type 1 diabetes mellitus. Pediatr Diabetes. 2008;9:472-9.

100. Rostami P, Setoodeh A, Rabbani A, Nakhaei-Moghadam M, Najmi-Varzaneh F, Rezaei N. A randomized clinical trial of insulin glargine and aspart, compared to NPH and regular insulin in children with Type 1 diabetes mellitus. Iran J Pediatr. 2014;24:173-8.

101. Cherubini V, Iannilli A, Iafusco D, Cardella F, Giamprini MS, Fanelli C, et al. Premeal insulin treatment during basal-bolus regimen in young children with type 1 diabetes. Diabetes Care. 2006;29:2311-2.

102. Macintosh MC, Fleming KM, Bailey JA, Doyle P, Modder J, Acolet $\mathrm{D}$, et al. Perinatal mortality and congenital anomalies in babies of women with type 1 or type 2 diabetes in England, Wales, and Northern Ireland: population based study. BMJ. 2006;333:177.

103. Middleton P, Crowther CA, Simmonds L. Different intensities of glycaemic control for pregnant women with pre-existing diabetes. Cochrane Database Syst Rev. 2012;8:CD008540.

104. Mathiesen ER, Kinsley B, Amiel SA, Heller S, McCance D, Duran S, et al. Maternal glycemic control and hypoglycemia in type 1 diabetic pregnancy: a randomized trial of insulin aspart versus human insulin in 322 pregnant women. Diabetes Care. 2007;30:771-6.

105. Pettitt DJ, Ospina P, Howard C, Zisser H, Jovanovic L. Efficacy, safety and lack of immunogenicity of insulin aspart compared with regular human insulin for women with gestational diabetes mellitus. Diabet Med. 2007;24:1129-35.

106. Moghissi ES, Korytkowski MT, DiNardo M, Einhorn D, Hellman R, Hirsch IB, et al. American Association of Clinical Endocrinologists and American Diabetes Association consensus statement on inpatient glycemic control. Endocr Pract. 2009; 15:353-69.

107. Umpierrez GE, Cuervo R, Karabell A, Latif K, Freire AX, Kitabchi AE. Treatment of diabetic ketoacidosis with subcutaneous insulin aspart. Diabetes Care. 2004;27:1873-8.

108. Moghissi ES. Addressing hyperglycemia from hospital admission to discharge. Curr Med Res Opin. 2010;26:589-98.

109. Udwadia F, Bhattacharyya A, Seshiah V, Sethi BK, Kumar S, Subbanna PK, et al. Intravenous insulin aspart in a hospital setting: results from an observational study examining patient outcomes and physician preferences. Diabetes Manag. 2012;2:103-10.

110. Bernard JB, Munoz C, Harper J, Muriello M, Rico E, Baldwin D. Treatment of inpatient hyperglycemia beginning in the emergency department: a randomized trial using insulins aspart and detemir compared with usual care. J Hosp Med. 2011;6:279-84.

111. Umpierrez GE, Hor T, Smiley D, Temponi A, Umpierrez D, Ceron $\mathrm{M}$, et al. Comparison of inpatient insulin regimens with detemir plus aspart versus neutral protamine Hagedorn plus regular in medical patients with type 2 diabetes. J Clin Endocrinol Metab. 2009;94:564-9.
112. Bergenstal RM, Tamborlane WV, Ahmann A, Buse JB, Dailey G, Davis SN, et al. Effectiveness of sensor-augmented insulinpump therapy in type 1 diabetes. $\mathrm{N}$ Engl $\mathrm{J}$ Med. 2010;363:311-20.

113. Doyle EA, Weinzimer SA, Steffen A, Ahern JA, Vincent M, Tamborlane WV. A randomized, prospective trial comparing the efficacy of continuous subcutaneous insulin infusion with multiple daily injections using insulin glargine. Diabetes Care. 2004;27:1554-8.

114. Gao GQ, Heng XY, Wang YL, Li WX, Dong QY, Liang CG, et al. Comparison of continuous subcutaneous insulin infusion and insulin glargine-based multiple daily insulin aspart injections with preferential adjustment of basal insulin in patients with type 2 diabetes. Exp Ther Med. 2014;8:1191-6.

115. Hirsch IB, Bode BW, Garg S, Lane WS, Sussman A, Hu P, et al. Continuous subcutaneous insulin infusion (CSII) of insulin aspart vs. multiple daily injection of insulin aspart/insulin glargine in type 1 diabetic patients previously treated with CSII. Diabetes Care. 2005;28:533-8.

116. Kawamura T, Urakami T, Sugihara S, Kim HS, Mochizuki M, Amamiya S. Changes in glycemic control and quality of life in pediatric type 1 diabetics with continuous subcutaneous insulin infusion of insulin aspart following multiple daily injection therapy. Clin Pediatr Endocrinol. 2008;17:39-47.

117. Raskin P, Bode BW, Marks JB, Hirsch IB, Weinstein RL, McGill JB, et al. Continuous subcutaneous insulin infusion and multiple daily injection therapy are equally effective in type 2 diabetes: a randomized, parallel-group, 24-week study. Diabetes Care. 2003;26:2598-603.

118. Lv WS, Li L, Wen JP, Pan RF, Sun RX, Wang J, et al. Comparison of a multiple daily insulin injection regimen (glargine or detemir once daily plus prandial insulin aspart) and continuous subcutaneous insulin infusion (aspart) in short-term intensive insulin therapy for poorly controlled type 2 diabetes patients. Int J Endocrinol. 2013;2013:614242.

119. DeVries JH, Snoek FJ, Kostense PJ, Masurel N, Heine RJ, Dutch Insulin Pump Study Group. A randomized trial of continuous subcutaneous insulin infusion and intensive injection therapy in type 1 diabetes for patients with long-standing poor glycemic control. Diabetes Care. 2002;25:2074-80.

120. Bode B, Strange P. Efficacy, safety and pump compatibility of insulin aspart used in continuous subcutaneous insulin infusion therapy in patients with Type 1 diabetes. Diabetes Care. 2001;24:69-72.

121. Bode B, Weinstein R, Bell D, McGill J, Nadeau D, Raskin P, et al. Comparison of insulin aspart with buffered regular insulin and insulin lispro in continuous subcutaneous insulin infusion: a randomized study in type 1 diabetes. Diabetes Care. 2002;25:439-44.

122. Chlup R, Zapletalova J, Seckar P, Chlupová L, Táncosová S, Reznícková M. Benefits of insulin aspart vs phosphate-buffered human regular insulin in persons with type 1 diabetes treated by means of an insulin pump. Biomed Pap Med Fac Univ Palacky Olomouc Czech Repub. 2004;148:27-32.

123. Bi YF, Zhao LB, Li XY, Wang WQ, Sun SY, Chen YH, et al. A 2-way cross-over, open-labeled trial to compare efficacy and safety of insulin Aspart and Novolin R delivered with CSII in 21 Chinese diabetic patients. Chin Med J (Engl). 2007;120:1700-3.

124. Alemzadeh R, Palma-Sisto P, Holzum M, Parton E, Kicher J. Continuous subcutaneous insulin infusion attenuated glycemic instability in preschool children with type 1 diabetes mellitus. Diabetes Technol Ther. 2007;9:339-47.

125. Dzygalo K, Szypowska A. Impact of insulins glulisine and aspart on postprandial glycemia after a high-glycemic index meal in children with type 1 diabetes. Eur $\mathbf{J}$ Endocrinol. 2014;170:539-45. 
126. Thrasher J, Bhargava A, Rees TM, Wang T, Guzman CB, Glass LC. Using insulin lispro with continuous subcutaneous insulin infusion is safe and effective in patients with type 2 diabetes: a randomized crossover trial of insulin lispro versus insulin aspart. Endocr Pract. 2014;4:1-28.

127. van Bon AC, Bode BW, Sert-Langeron C, et al. Insulin glulisine compared to insulin aspart and to insulin lispro administered by continuous subcutaneous insulin infusion in patients with type 1 diabetes: a randomized controlled trial. Diabetes Technol Ther. 2011;13:607-14.

128. Weinzimer SA, Ternand C, Howard C, Chang CT, Becker DJ, Laffel LM, et al. A randomized trial comparing continuous subcutaneous insulin infusion of insulin aspart versus insulin lispro in children and adolescents with type 1 diabetes. Diabetes Care. 2008;31:210-5.

129. Wittlin SD, Marcus AO, Weng CS, Howard CP, Schorr AB, CONTROL Study Group. Evaluation of treatment satisfaction associated with the use of insulin aspart in continuous subcutaneous insulin infusion. Diabetes Technol Ther. 2008;10:1-10.

130. Tamborlane WV, Renard E, Wadwa RP, Blevins T, Jacober SJ, Liu R, et al. Glycemic control after 6 days of insulin pump reservoir use in type 1 diabetes: results of double-blind and open-label cross-over trials of insulin lispro and insulin aspart. J Diabetes. 2015;7:270-8.

131. Bartolo PD, Pellicano F, Scaramuzza A, Sardu C, Casetti T, Bosi E, et al. Better postprandial glucose stability during continuous subcutaneous infusion with insulin aspart compared with insulin lispro in patients with type 1 diabetes. Diabetes Technol Ther. 2008;10:495-8.

132. Brunner G, Hirschberger S, Sendlhofer G. Postprandial administration of the insulin analogue insulin aspart in patients with type 1 diabetes mellitus. Diabet Med. 2000;17:371-5.

133. Luijf YM, van Bon AC, Hoekstra JB, Devries JH. Premeal injection of rapid-acting insulin reduces postprandial glycemic excursions in type 1 diabetes. Diabetes Care. 2010;33:2152-5.

134. Bott U, Ebrahim S, Hirschberger S, Skovlund SE. Effect of the insulin analogue insulin aspart on quality-of-life and treatment satisfaction in type 1 diabetic patients. Diabet Med. 2003;20:626-34.

135. Kurtzhals P, Schäffer L, Sørensen A, Kristensen C, Jonassen I, Schmid C, et al. Correlations of receptor binding and metabolic and mitogenic potencies of insulin analogs designed for clinical use. Diabetes. 2000;49:999-1005.

136. Ma Z, Christiansen JS, Laursen T, Wu C, Lauritzen T, Parkner $\mathrm{T}$, et al. Effects of human insulin and insulin aspart preparations on levels of IGF-I, IGFBPs and IGF bioactivity in patients with type 1 diabetes. BMC Endocr Disord. 2014;14:35.

137. Hattori N, Duhita MR, Mukai A, Matsueda M, Shimatsu A. Development of insulin antibodies and changes in titers over a long-term period in patients with type 2 diabetes. Clin Chim Acta. 2014;433:135-8.

138. Lindholm A, Jensen LB, Home PD, Raskin P, Boehm BO, Råstam J. Immune responses to insulin aspart and biphasic insulin aspart in people with type 1 and type 2 diabetes. Diabetes Care. 2002;25:876-82.

139. McCance DR, Damm P, Mathiesen ER, Hod M, Kaaja R, Dunne $F$, et al. Evaluation of insulin antibodies and placental transfer of insulin aspart in pregnant women with type 1 diabetes mellitus. Diabetologia. 2008;51:2141-3.

140. Holmberg H, Mersebach H, Kanc K, Ludvigsson J, Insulin Aspart Study Group on Immunogenicity. Antibody response to insulin in children and adolescents with newly diagnosed Type 1 diabetes. Diabet Med. 2008;25:792-7.

141. Hod M, Damm P, Kaaja R, Visser GH, Dunne F, Demidova I, et al. Fetal and perinatal outcomes in type 1 diabetes pregnancy: a randomized study comparing insulin aspart with human insulin in 322 subjects. Am J Obstet Gynecol. 2008;198(186):e1-7.
142. Frier BM, Ewing FM, Lindholm A, Hylleberg B, Kanc K. Symptomatic and counterregulatory hormonal responses to acute hypoglycaemia induced by insulin aspart and soluble human insulin in Type 1 diabetes. Diabetes Metab Res Rev. 2000; 16:262-8

143. Gao Y, Pan CY, Zou DJ, Xu ZR, Liu XM, Guo XH. Postprandial glycemic control using insulin aspart with NPH in inadequately controlled diabetics. Zhonghua Yi Xue Za Zhi. 2009;98:1960-3.

144. Kristensen PL, Pedersen-Bjergaard U, Beck-Nielsen H, Nørgaard K, Perrild H, Christiansen JS, et al. A prospective randomised cross-over study of the effect of insulin analogues and human insulin on the frequency of severe hypoglycaemia in patients with type 1 diabetes and recurrent hypoglycaemia (the HypoAna trial): study rationale and design. BMC Endocr Disord. 2012;12:10.

145. Pedersen-Bjergaard U, Kristensen PL, Beck-Nielsen H, Nørgaard K, Perrild H, Christiansen JS, et al. Effect of insulin analogues on risk of severe hypoglycaemia in patients with type 1 diabetes prone to recurrent severe hypoglycaemia (HypoAna trial): a prospective, randomised, open-label, blinded-endpoint crossover trial. Lancet Diabetes Endocrinol. 2014;2:553-61.

146. Swanson CM, Potter DJ, Kongable GL, Cook CB. Update on inpatient glycemic control in hospitals in the United States. Endocr Pract. 2011;17:853-61.

147. Umpierrez GE, Isaacs SD, Bazargan N, You X, Thaler LM, Kitabchi AE. Hyperglycemia: an independent marker of inhospital mortality in patients with undiagnosed diabetes. J Clin Endocrinol Metab. 2002;87:978-82.

148. Dungan KM, Sagrilla C, Abdel-Rasoul M, Osei K. Prandial insulin dosing using the carbohydrate counting technique in hospitalized patients with type 2 diabetes. Diabetes Care. 2013;36:3476-82.

149. Chawla M, Malve H, Shah H, Shinde S, Bhoraskar A. Safety of intravenous insulin aspart compared to regular human insulin in patients undergoing ICU monitoring post cardiac surgery: an Indian experience. J Diabetes Metab Disord. 2015;14:20.

150. Senstius J, Harboe E, Westermann H. In-vitro stability of insulin aspart in simulated continuous subcutaneous insulin infusion using a MiniMed 508 insulin pump. Diabetes Technol Ther. 2007;9:75-9.

151. Senstius J, Poulsen C, Hvass A. Comparison of in vitro stability for insulin aspart and insulin glulisine during simulated use in infusion pumps. Diabetes Technol Ther. 2007;9:517-21.

152. Senesh G, Bushi D, Neta A, Yodfat O. Compatibility of insulin Lispro, Aspart, and Glulisine with the Solo MicroPump, a novel miniature insulin pump. J Diabetes Sci Technol. 2010;4:104-10.

153. Woods RJ, Alarcón J, McVey E, Pettis RJ. Intrinsic fibrillation of fast-acting insulin analogs. J Diabetes Sci Technol. 2012;6:265-76.

154. Poulsen C, Langkjaer L, Worsøe C. Precipitation of insulin products used for continuous subcutaneous insulin infusion. Diabetes Technol Ther. 2005;7:142-50.

155. Poulsen C, Langkjaer L, Worsøe C. Precipitation of insulin aspart and insulin glulisine products used for continuous subcutaneous insulin infusion. Diabetes Technol Ther. 2007;9:26-35.

156. Kerr D, Morton J, Whatley-Smith C, Everett J, Begley JP. Laboratory-based non-clinical comparison of occlusion rates using three rapid- acting insulin analogs in continuous subcutaneous insulin infusion catheters using low flow rates. J Diabetes Sci Technol. 2008;2:450-5.

157. Naik S, Kerr D, Begley J, Morton J. Influence of local skin temperature and choice of insulin analog on catheter occlusion rates during continuous insulin infusion: an exploratory study. Diabetes Technol Ther. 2012;14:1018-22. 
158. Pickup JC, Sutton AJ. Severe hypoglycaemia and glycaemic control in Type 1 diabetes: meta-analysis of multiple daily insulin injections compared with continuous subcutaneous insulin infusion. Diabet Med. 2008;25:765-74.

159. Lloyd A, Townsend C, Munro V, Twena N, Nielsen S, Holman A. Cost-effectiveness of insulin aspart compared to human insulin in pregnant women with type 1 diabetes in the UK. Curr Med Res Opin. 2009;25:599-605.

160. Liebl A, Seitz L, Palmer AJ. Health Economics Analysis of Insulin Aspart vs. Regular Human Insulin in Type 2 Diabetes Patients, Based on Observational Real life Evidence from General Practices in Germany. Exp Clin Endocrinol Diabetes. 2014;122:517-22.

161. Palmer JL, Goodall G, Nielsen S, Kotchie RW, Valentine WJ, Palmer AJ, et al. Cost-effectiveness of insulin aspart versus human soluble insulin in type 2 diabetes in four European countries: subgroup analyses from the PREDICTIVE study. Curr Med Res Opin. 2008;24:1417-28.
162. Aagren M, Luo W, Moës E. Healthcare utilization changes in relation to treatment intensification with insulin aspart in patients with type 2 diabetes. Data from a large US managedcare organization. J Med Econ. 2010;13:16-22.

163. Saunders R, Lian J, Karolicki B, Valentine W. The cost-effectiveness and budget impact of stepwise addition of bolus insulin in the treatment of type 2 diabetes: evaluation of the FullSTEP trial. J Med Econ. 2014;17:827-36.

164. Heise T, Hövelmann U, Brøndsted L, Adrian CL, Nosek L, Haahr H. Faster-acting insulin aspart: earlier onset of appearance and greater early pharmacokinetic and pharmacodynamic effects than insulin aspart. Diabetes Obes Metab. 2015; 17:682-8.

165. Bode B, Hyveled L, Tamner SC, Ybanez P, Demissie M. Improved post-prandial control with faster-acting insulin aspart in subjects with type 1 diabetes using CSII. Diabetes. 2015;38(Suppl 1):A235. 